SERVIÇO DE POS-GRADUAÇAO DO ICMC-USP Data de Depósito: 19/05/2002

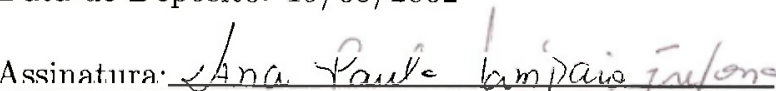

\title{
Sistema de navegação de robôs móveis autônomos para o transporte de documentos ${ }^{1}$
}

\author{
Rodrigo Elias Bianchi
}

Orientadora: Prof ${ }^{a}$ Dr ${ }^{a}$ Roseli Aparecida Francelin Romero

Dissertação apresentada ao Instituto de Ciências Matemáticas e de Computação - ICMC/USP, como parte dos requisitos necessários para obtenção do título de Mestre em Ciências de Computação e Matemática Computacional.

USP - São Carlos

Maio/2003

${ }^{1}$ Trabalho realizado com apoio financeiro da FAPESP e CNPq. 
A Comissão Julgadora:

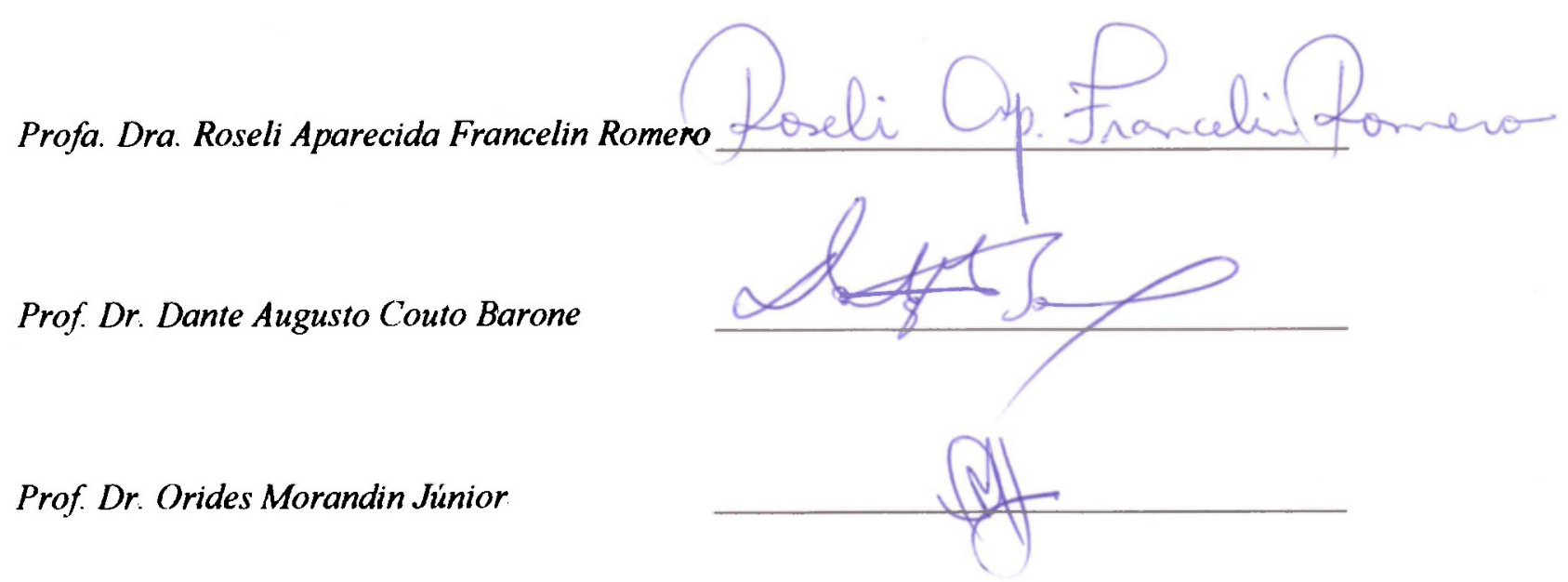


Este documento foi preparado utilizande-se o format ador de textos LTEX. Sua bibliografia é gerada automaticamente pelo BiBl' $\mathrm{L}_{\mathrm{E}}^{\mathrm{X}}$, utilizando o estilo $\Lambda_{\text {palike. }}$

(C) Copyright 2003 - Rodrigo Elials Biandhi Todos os direitos Reservados 
Resumo

Nessa dissertageno a investigade o uso de mótodes probabilísticos para a navegacäo de rolos móveis antomomos. () ol jetivo principal ó o desemvolvinento de un software para navegaçào de um robô móvel que seja capaz de transportar documenos de forma antonoma entre loceis distantess. como as diversals salas do

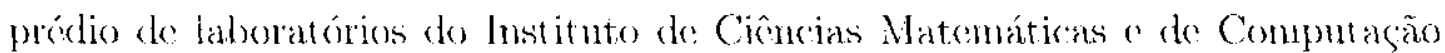

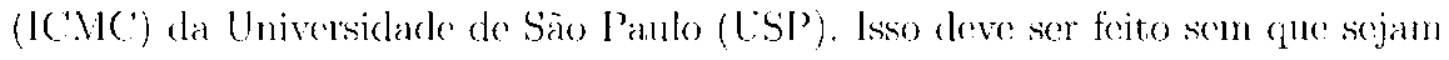
necessárias modificacoes de qualçuer tipo no anbionue.

Para isso. o software deve ser capaz de: (1) cstinar a posição do robô sem

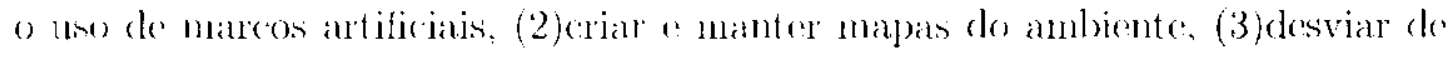
obstáculos cstáticus e dinânicos. o (4) calcular a trajotória entre os pontos em que 1) robe deverá revelore cent regar decumentes.

Cin sistema de nawegacăo, utilizando os métorlos probabilísticos de mape:amento Octupancy Grid e de localizaçăo Monte Carlo. foi implementado e diver-

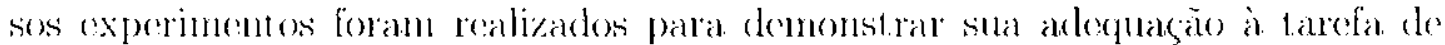
entrega de documentos. Esses métodos foram testados em um ambiente real do IC.MC-LSP, utilizande-se o robo móved l'ioner J. 


\section{Abstract}

In this work, we investigate the use of probabilistic mothods for antonomous mobile robots navigation. The main goal is to develop a navigation software for a mobile robot. which must be able to transport documents autonomously between distant places. This must be done without any modification on the robot enviromment.

The environnents that this robot an act on could be. for example, the laboratories building of the Institute of Mathematics and Computer Sciences (IC.MC) at the University of São Paulo (USP).

In order to achieve this, the software must be able to: (1)estimate the robot position without using artificial landmarks, (2)build and maintain environment maps. (3)avoid static and dynamical olstacles, and (4)calculato the path between the places where the robot is expected to get and deliver documents.

A navigation system that uses the probabilistic mohods called Ocenpancy (irid Wapping and Montr Carlo Localization was implemented. In order to shlow the adeguacy of such a systen to the doenments delivery task, several experiments have been performed. These methods have been tested in a real convironment at ICWC-USP. by using the Pionece I mobile robot 
À minha mäe. (que semu)re fez o que cra melhor para mim, mesmo gue nano fosse o melhor para ela. So não fosse por seu apoio incondicional, esse trabalho naios serial possivel. 


\section{Agradecimentos}

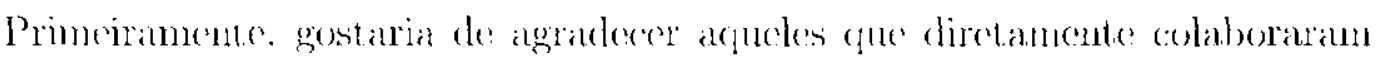

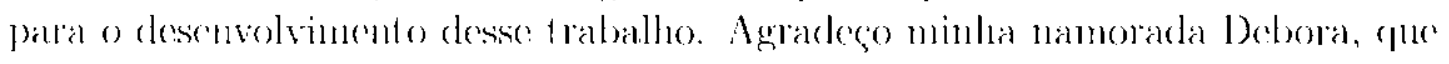
sempre csteve presente e fez una revisáa mimuciosa desse lexto. Agradeco ao

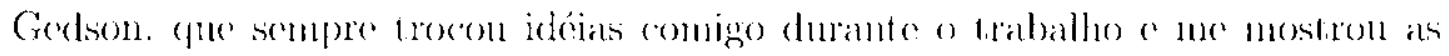
ferramentas disponivels no I.ABIC. Agradeço à Roseli pela oportunidade que no den. orientiagäo o cxtroma confiança depositada ens mim. Agradeco ao Ronaldo pelos estilos do LTFX e pola consultorial.

Agradeco minla märe Neida, que sempre que vinla a São Carlos. me ajudava no que podia para me deixar com mais tempo livre pra trabalhar. alćm do sempre estar interessada no meu trabalho, mo ajudando em várias decisòes. Agradeço men pai Roberto. yue de Fo\% do lguaçu por intemet, revisou o portuguis dessia dissertaçäo. Agradeco aos dois por sempre acreditarem $\mathrm{cm}$ mim.

Agradego tannbén todes us mens anigos, sem o suporte de voces acho que ficaria louro trabalhando sozinho turnos de 24 horas e dormiudo (quando possível) 6 horas para concluir essia dissertaçoo.

Agradeco também aos professores e colegas do L A B BlC com os quais sempre

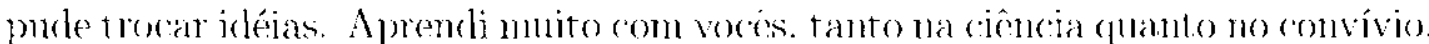

Agradeço a professora Sandra do NILC que me apoiou om uma época que precisei monilo.

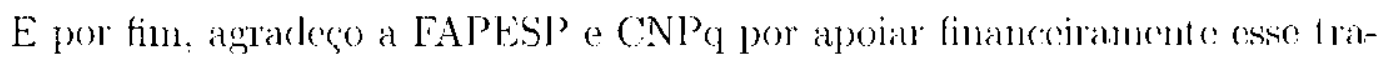
ballos. 


\section{Sumário}

1 Introdução 1

2 Robótica sob a Perspectiva da Inteligência Artificial 5

2.1 Robós a Robós Intchigentes . . . . . . . . . . . . . . 5

2.2 Paradigmas da Robóticat . . . . . . . . . . . . . .

2.2 .1 Paradigma Hicrár(uico . . . . . . . . . . . 7

2.2 .2 Paradigma Reativo . . . . . . . . . . 8

2.2 .3 Paradigna Híbrido Reativo/Deliberativo ....... 8

2.3 Arquitcturas Robúticats . . . . . . . . . . . . . . . . 9 9

2.3.1 Nested Hienarchical Controller (Paradigma Hicrárquico) , 9

2.3 .2 Subsumption (Paradigma Reativo) . . . . . . . . 10

2.3.3 Saphira (Paradigma Híbrido) . . . . . . . . . . 11

2.4 Navegagà . . . . . . . . . . . . . . . . . 11

2.4 .1 Localizacan . . . . . . . . . . . . . . 12

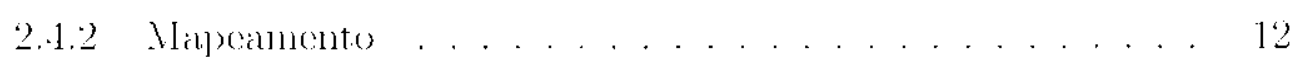

2.4 .3 Planejantento de Trajotoria . . . . . . . . . . 12

2.5 Consideragon Finais . . . . . . . . . . . . . . . 13

3 Localização de Robôs Móveis $\quad 15$

3.1 Catogorias do Problema de Localizanào . . . . . . . . . 15

3.1 .1 Métodos Locais Versus Globais . . . . . . . . . 16

3.1 .2 Ambientes Estáticos Vorsus Dinaniros . . . . . . . . 16

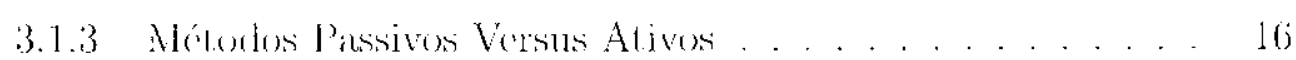

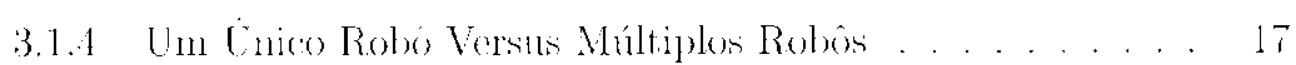

3.2 Localizacão de Markov . . . . . . . . . . . . . . . . 17

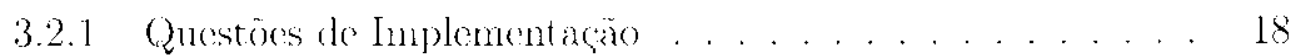

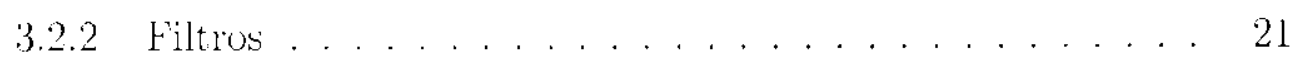

3.3 Consideraçoes Finais . . . . . . . . . . . . . . . . . 23 
1 Mapcamento 25

4.1 Tipos de Mapras . . . . . . . . . . . . . . . . . . 26

4.2 Occupancy Grid . . . . . . . . . . . . . . . . . . 28

4.3 Occupancy Grid com Localização Monte Carlo . . . . . . . . . . 30

4.4 Consideraçoes Finais . . . . . . . . . . . . . . . . . . . . 32

5 Planejamento de Trajetória 33

5.1 Campos Potenciais . . . . . . . . . . . . . . . 34

5.2 Vertor Finld Histogrom . . . . . . . . . . . . . . . . . . 35

5.3 Consideraçōes Finais . . . . . . . . . . . . . . . . . . . . 37

6 Desenvolvimento do Sistema 39

6.1 J)excrica do Sistema . . . . . . . . . . . . . . . . . 39

6.1.1 Hardware Roboitico . . . . . . . . . . . . . . . . . 40

6.1 .2 Interface . . . . . . . . . . . . . . . . . . 11

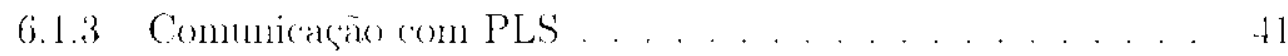

6.1.4 Gerador do Logs .................... 41

6.1 .5 Localizana . . . . . . . . . . . . . . . . . 41

6.1.6 Ferramenta de Mapeamento . . . . . . . . . . . . . 42

6.1.7 Navegacano (Controle do'Trajetória) . . . . . . . . . . . 42

6.2 Consideraçoes Finais . . . . . . . . . . . . . . . . . 42

7 Resultados $\quad 45$

7.1 Performance da Iondizaçă . . . . . . . . . . . . . 45

7.2 Performance do Mapeamento . . . . . . . . . . . . . . . . . 47

7.3 Performance do Controle de Trajetória . . . . . . . . . . . . . 51

7.4 Consideracoes Finais . . . . . . . . . . . . . . . . . 53

8 Conclusões e Trabalhos Futuros

$\begin{array}{ll}\text { Referências Bibliográficas } & 57\end{array}$ 


\section{Lista de Figuras}

2.1 Pararligma Hicrárquico . . . . . . . . . . . . . . . . . 7

2.2 Paradigma Roalivo . . . . . . . . . . . . . . . . 8

2.3 Paradigma llíbrido . . . . . . . . . . . . . . . . . . . 9

2.4 Excmplo da Arepuitetura Subsumplion . . . . . . . . . . 11

3.1 Probabilidade $p_{n}\left(d_{i} \mid l\right)$ de que a leitura $s_{i}$ seja mais curta do que o esperado. (Fox et al., 1998a) ............... 22

1.1 Atualização do mapa por un dos raios projetados pelo sensor. O círculo representa o robô. A seta indica o raio. A parte em rinza caro no canto superior direito do mapa r mu obstáculo.

4.2 Estratégia de Mapeamento: Os círculos representam o robó nas posiçoes ondo houve realizaça do um cielo de localizaçao e mapeannento.

j.1 Fxemplo de Campos Potenciais . . . . . . . . . . . 35

6.1 Arquitetura do Sistema. . . . . . . . . . . . . . 40

7.1 Planta do corredor do prodio de Laboratórios do ICNC-CSP. . . 48

7.2 Corredor do prédio de Laboratórios mapeado por Occupancy Grid. Os crros de odometria acumulados inutilizaram o mapa gerado. . 48

7.3 Corredor do prédio de Laboratónios mapeado por Oceupancy Grids com hocalização Montc: Carlo. . . . . . . . . . . . . . . . . . . . 49

7.4 Mapa com corregäo de posição de um ambiente simulado contendo $u$ ciclo. . . . . . . . . . . . . . . . . . . 50

7.5 Malpa sem corregào de posigaio de um ambiente simulado contendo nun ciclo. . . . . . . . . . . . . . . . . . . . . . . . 50

7.6 a) Um ambiente cíclico relativamente pequeno onde o erro não foi grave. b) Detalhe do ponto onde deveria ser feito o fechamento do ciclo on un ambiente trós vezes maion que o ilustrado on (a). . 51 
7.7 Caminho percorrido pelo robô em um ambiente simulado para passar pelos poutcos (círeulos) definides pelo usirírio. . . . . . . . . 51

7.8 Caminho percorrido pelo robo om um antbiente real para passar pelos pontos (círculos) definidos pelo usuário. Nesse caminho o robó encontrou très obstáculos (retângulos) não previstos no mapa. 52 


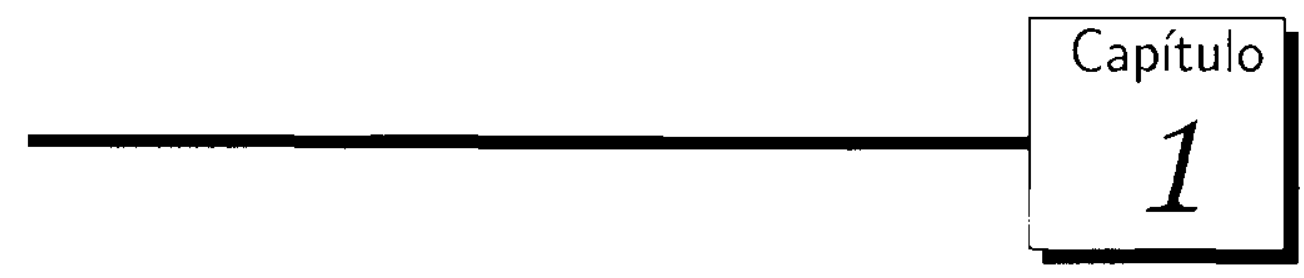

Introdução

$\mathcal{A}$

pesquisa na área de robós móveis que operam em ambientes não ostruturados prove desafios bem interesiantes. Dentre estes desafios, a

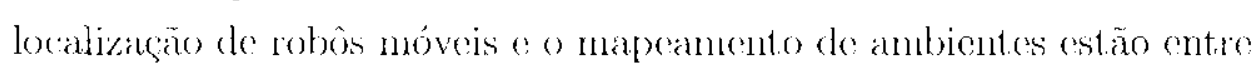
os mais fundamentais. Devido a ruídos, falta de precisão e a utilização dos robó móveis em ambiontes dinámicos ${ }^{2}$. os dados provenientes dos sensores possuem um alto gran de incertera. Isso torna essas tarefas ainda mais complexas.

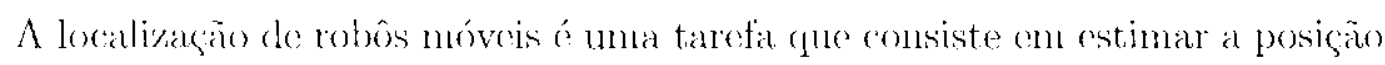
do nun robô movel por meio de um mapa do ambiente em que o robô está inserido c informagões obtidas de seus sensores. A localizagão é um dos componentes mais importantes de um sistema de navegagçón de robos móveis autônomos, como pode ser precobido pela afirmangão do Cox (1991):

"Usar informaçäo sensorial para localizar o robô em seu ambiente é o problema mais fundamental para dar capacidades autônomas a um. robô móvel".

O mapeamento tem o objotivo de criar um mapa do ambiente do robó explorando o mesino de forma autônona ou contrulado por um ser hmmano, obtendo

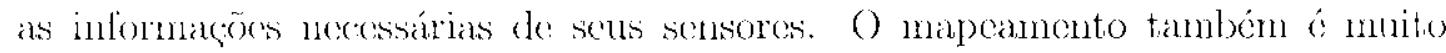

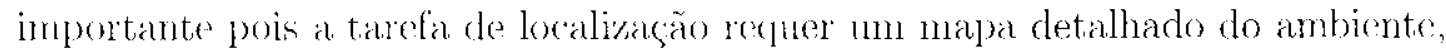
o que pode scr difícil de se conseguir manualmente ou por moio de plantas, uma vez que estas geralnente não contém informaçoes sobre móveis e outros objetos pertencentes alo ambiente.

\footnotetext{
'Ambientes commens, nào modificados para facilitar o uso de robôs.

${ }^{2}$ Ambientes em que o robô pode encontrar objetos não presentes na sua representação do munklo on hà encontral algum que stava presente.
} 
Nesse projeto, foram integrados métodos probabilísticos capazes de realizar essas tarefas com o objetivo de descrvolver um sistema de navegaçào para um robô móvel que seja capaz de transportar documentos de forma autonoma entre locais distantes. Esses métodos são robustos, uma vez que levan em consideração explicitamente a incerteza nos dados sensoriais.

Esse projeto é relacionado a um projeto maior, chanado $\mathrm{ARMOSH} \mathrm{R}^{3}$ que conton con o apoio da FAPESP (Processo no.0/02959-3). () projeto ARMOSH tem como unn de sens objetivos a implementação de diversos algoritmos para robós móveis tanto con nivel de software quanto de hardware. Dentre estes algoritmos. se destacam os algoritmos de localização e mapeaunento.

Portanto, além do desenvolvimento de $11 m$ sistema de navegação, o presentte trabalho possui também o objetivo de investigar e desvendar algoritmos de localizaciano e mapeanento, contribuindo fortenente para a execucäo do projeto AR.MOSH.

O ambiente real utilizado para os testes do sistema foi o andar térreo do prédio dos laboratórios do ICMC ${ }^{4}$. Nesse prédio. o robô pode andar entre os diversos laboratórios, a copa, seção técnica de informática. sala de estar, entre ontros. Esse prédio se mostra ideal para os testes pois ć amplo e, alo percorre-lo, vários exros de odometria são gerados e devem scr compensados pelo algoritmo do localização.

Para tanto, além dos algoritmos de localização e mapeannento, foram desenvolvidos outros algoritmos mais básicos como o de desvio de obstáculos e controle da trajetória entre pontos en um mapa.

Por fim, um software que integra todos estes algoritmos o disponibiliza uma interface para comandar o robó foi implementado e com ele foram efetuados vários experimentos. Os resultados indicam que a abordagem probabilística aos problemas de naveganão leva ib un sistema robusto e com alto nível de automomia.

Fsssa dissertação está organizada da seguinte forma.

No Capitulo 2. sào introduzidos alguns conceitos innportantes focalizando a área de robótica sob o ponto de vista da inteligência artificial.

No Capítulo 3, são apresentados o problema da localização de robôs móveis. suas categorias e as técnicas mais utilizadas para solucioná-lo.

No Capítulo 4, é descrito o método utilizado nesse trabalho para realizar o mapeamento de ambientes.

No Capítulo 5, o planejanonto de trajetória, que é a parte da tarefa de nave-

\footnotetext{
${ }^{3}$ Aprendizado de Robos Móveis via Software e Hardware.

${ }^{4}$ Instituto de Ciências Matemáticas e de Computação da Universidade de São Paulo.

"Processo de estimar o deslocimento de um véculo medindo a rotacio dos eixos de suas roclins.
} 
gargäo responsável por definir os comandos motores, á apresentada e dois métodes ntilizados para cesse fim são descritos

No Capítulo 6, a arquitetura e as funcionalidades do sistema de navegação proposto são apresentadas.

No Capítulo 7. os progressos alcançados säo discutidos.

Por fim, no Capitulo 8. conchusons a respeito dos experimentos realizades bem como uma série de trabalhos futuron são apresentados. 



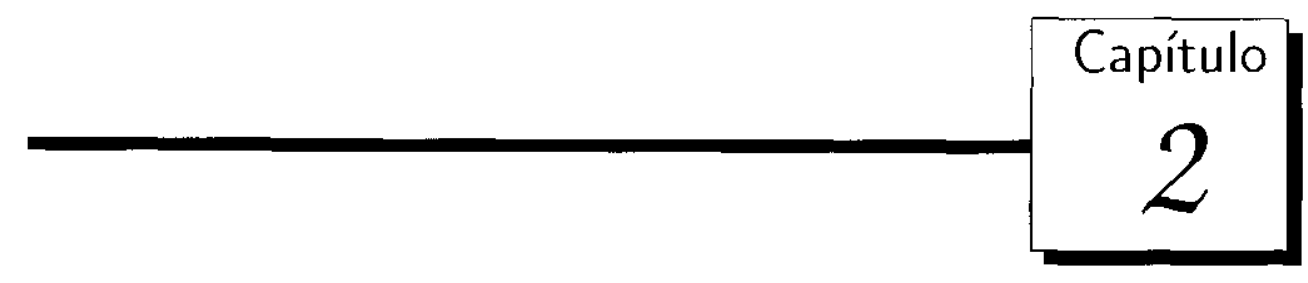

\section{Robótica sob a Perspectiva da Inteligência Artificial}

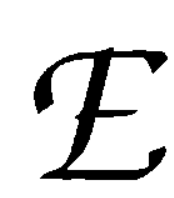

sse capítulo tem o objetivo de esclarecer questōes referentes a natureza dos robôs a fornecer fundamentos básicos solre o desenvolvimento na área de robótioa do ponto de vista da inteligencia artificial.

Para isso, concentes importantes. como os patradigmats da robóticat. arcuntelulas e os problemas da navegacão serão introduzidos.

\subsection{Robôs e Robôs Inteligentes}

A maiomia das pessoas, quando pensa em robos, logo imagina um dispositivo mecatronico e antropomórfico (semelhante ao homenn). Porém, unn robô náo precisa obrigatoriamente ter essas duas características.

Na pega de Karel Capek chamada R.L.R. (Rossums Lniversal Robots). do

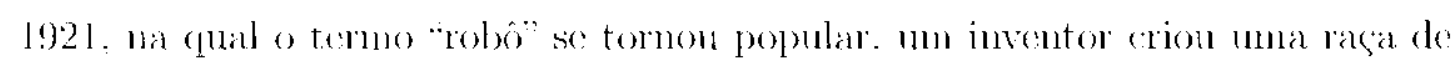
trabalhardores feitos de $11 m$ repositório de partes biológicas ao invés de mecânicas e cletrônicas (Murphy, 2000).

Inúneras implementaçoes de robós semelhantes a carros, aviões, aspiradores le pó, cutre ontros, mostram que há uma tendencia en projetar o formato dos robos de acordo com a fumgão que o mesmo dosempenha e não simplesmente baseá-lo no formato do seres humanos.

Muitas vezes, espera-se que alem do formato, o robo tenha um modo de racio-

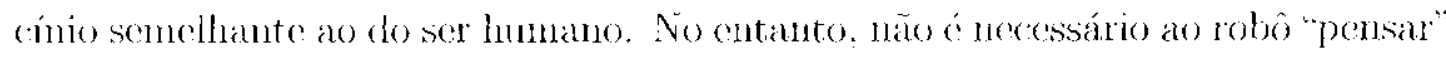
como o homem para due ele possa desempenhar alguma fungão bom sstabolecida.

Mas o que são robôs? Para responder a esta pergunta, devenos analisar primerimente o contexto no qual ela foi proferida pois no início da década do 60, honve una divisão no caminho evolutivo da área. Una linha de pesquisadores 
seguin o caminho da robótica industrial, enguanto outros dedicaranı-se à criação de robos para o programa espacial (na maioria. cepploradores planctírios).

O esforço no desenvolvimento de robôs industriais concentrou-se no projeto de bragos robotizades para aplicacoose de mamufatura. Para estas aplicaçoes, o importante é ter precisão e repetição nas linhas de nontagen. que são ambicntes altamente estruturados onde é possivel garantir ao robo (nne so cle foi programado para pegar una peça na coordenada $x, y . z$, quando ele executar esta ação, a peça estará lá

Desta forma, muitos destes robos são programados para realizar uma série de movimentos muito bem definida, e eles os fazcm sem precisar monitorar on representar o ambiente, e sem a mínima necessidade de "inteligoncial".

Neste contexto, segundo Arkin (1998), a Robolics Industry Association (RIA). define:

\footnotetext{
"Um robó é um manipulador re-programánel e multifuncional projetado para mover matenal, pecas. ferramenias. ou dispositwos especializados por meino de movmentos varianeis programados para a realizaçào de uma variedade de tarefas."
}

Poróm esta definiçăo não se aplica ao ontro rano da divisào ocorrida no caminho ovolutivo dat robótica. Estia outra linha de pesquisa cvoluiu da simples teleoperação (robôs controlados manualmente a distância) para a construçắo de robôs autônomos, dando origem a um nova subárea da robótica chamada "AI Robotice": que visa a pesculusa e o desenvolvimento de robos inteligentes. Lima definição de robò inteligente foi dada por Murphy (2000):

"Un robô inteligente á uma criatura mecânica que pode funcionar autonomamente."

Ele ó inteligente pois nào realiza tamefas de modo repetitivo e pré-determinade. Funcionar autonomamente significa quo cle pode operar de modo auto-contido, o.

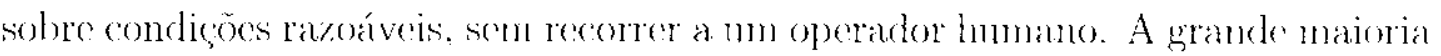
dos robôs inteligentes faz parte do grupo dos robós móveis. (jue são robôs dotados do caparidades do locomocão.

Como o presente trabalho faz parte do ramo "Al Robotics". deste ponto en diante, quando falamos em robótica, estamos falando em robótica do ponto do vista da IA (Inteligencia Artificial). 


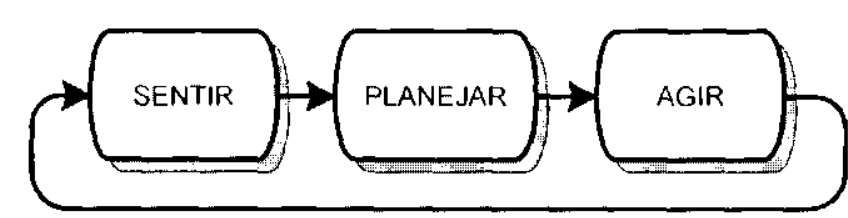

Figura 2.1: Paradigna Hierárquico

\subsection{Paradigmas da Robótica}

Un paradigna é una filosofia on conjunto de concepgoce e/on técnicas que calacterizan mua abordagem a una dasse de problemas. Om paradigma robótico caracteriza a forma em que a "inteligência" pode ser estruurada em robòs. Très primitivas básicas e a forma de sua organizaçao, diferencian os paradignas da robótica. sào das: SENTIR. PLANEJAR e AGIR. A SENTIR di\% respeito as tarofas relacionadas com a recuperacăo de informaçoes do ambiente em que o robô está inserido. por meio de scus sensores. A PLANEJAR está relacionada ao processo de recober informacoocs e a partir dolas, produzir tarelas a serem conduzislas pelo robò. Por fim. AGIR produz comaundos diretamente aos atuadores do robo (notores on guaisfuer dispositivos (pue modificpuem at ivanente o ambionte).

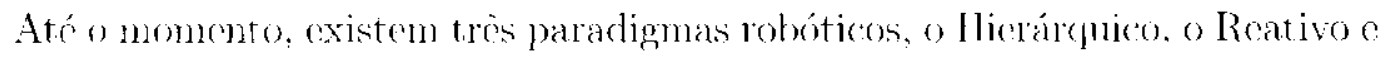
"Hóbrido Reativo/ Deliberativo. A seguir. Cada un deles sera descrito de forma sucinta Murphy $(2000)$.

\subsubsection{Paradigma Hierárquico}

O paradigma hierárquico foi o primeiro paradigma robótico. Nestee as primitivas robóticals estáo organizadas da seguinte maneira. Primeiro o realizada a primitim SENTIR. que obtém dados dos sensores a as integra em um modelo de mundo global. Fu seguida, a prinitiva PLANEJAR ó executada, a qual irá interpretar o modelo de mundo global e fornecer tarefas à primitiva AGIR que irá comandar os nódulos de controle de baixo nível do robó. Essa organizaçào, que pode ser observada na Figura 2.1, é cíclica, on scjar após agir, o robó reiniciaráa archo, sentindo, plancjando o então agindo novamente.

O principal problema desse paradigma fo o lompo de resposta. Os processos de criacão de modelos de mundo complexos e de plancjamento são computacionalmente caros, e conno nesse paradigna as primitivas estäo organizadas seqüencialmente, o robo deve esperar o término de todo o cíclo para "sentir" o ambiente e identificar se suas açoes foran realizadas corretamente assim como as mudanças causadas por outros agentes.

Lin dos primeiros robôs móveis da IA foi Shakey (Shanahan. 1999). Ele segue o 


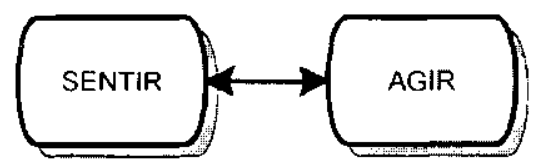

F"igura 2.2: Paradigma Reative

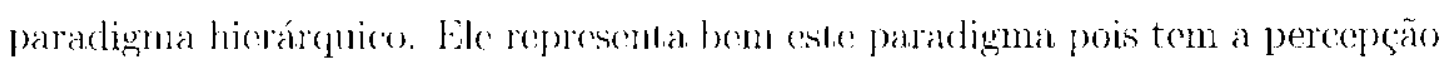
do mundo totahmente separada da açăo. Ele usa um plancjaclor chamako STRIPS. o cual utiliza a análise nocios-fins para inferir açoes tomando como entrada um modelo simbólico do mundo obtido anteriormente ao planejanento.

\subsubsection{Paradigma Reativo}

Analisande cstudes de psiróloges sobre o comportamento de animais, os roboticistas criaram um novo paradigma, o paradigma reativo. Vele, como pode ser observado na Figura 2.2, a primitiva. PLANEJAR foi complenamente climinada com intuito do fazer um mapeamento direto entre percepsão e ação.

O paradigna reativo é orientado a comportamentos. Comportanentos podem ser vistos cono "olos" que ligam a percepuão à açono. Tambén poden ser vistos como midades básicals a partir das chais sistemas complexes podem ser desenvolvidos pela integração do partes simples.

() comport annento geral do robó ćalcancado por meio da combinaçäo de vários (omportamentos independentes. Essa independencia implica em que as primitivas SFNTIR e AGIR säo locais a cada comportanento. Desal forma, vários comandos motores independentes são gerados c devem ser integrades de algum modo como veremos na Seção 2.3 na prágina opestat.

Modelos de mundo săo expressamente proibidos no paradigna reativo. Robôs

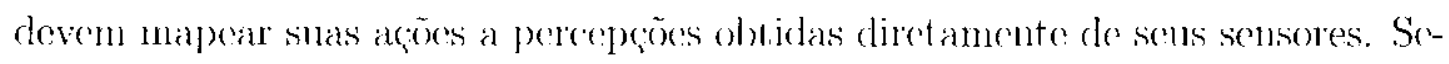
gundo Brooks (1991). un dos mais importantes defensores da abordagem reatival:

"O melthor modelo do mundo é cle prónrio."

\subsubsection{Paradigma Hibrido Reativo/Deliberativo}

Apesar do sucesso alcançado com o paradigma reativo demonsirario por implementacoes de comportanentes, como desviar de obstácules o seguir motas simples

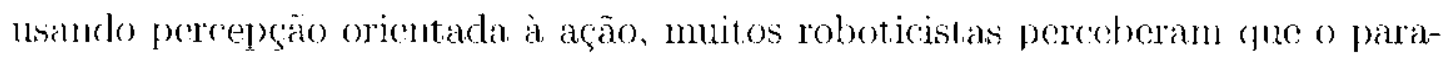
digma reativo não resolveria lodos os problemats. Muitas tarefas reguerem che us robos tenlame uma certa memória de uma representacăo de munclo, como por exconplo o mapeamento e a localização, tarefas cruciais para que num robô possa navegal de forma autonoma por longas distâncias e grandes períodos de tempo. 


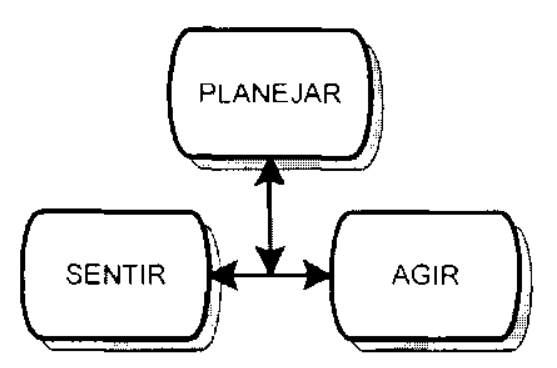

Figura 2.3: Paradigma Júbrido

() paradigna híbrido é (anpar de unir os dois paradignas anteriores de forma a năo tomal os robós lentos como no paradigma hierárquico, e ainda assim realizar plancjanentos due possuem alto custo computacional.

Como pode ser visto ma ligura 2.3, a primitiva PLANEJAR estáa presenté. porén näo majs ligada seqüenciahnente com as outras. Neste paradigma, a organizarga é do tipo PLANEJAR, SENTIR-AGIR. Isso significa que o planejamento

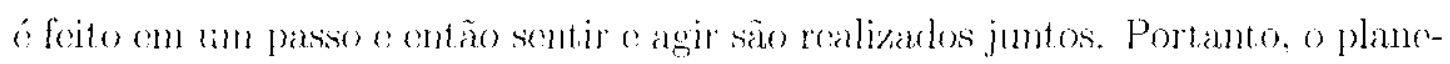
janı'nto não faz parte do ciclo de percepçào-açâo, interagindo nessa organização somente quando tem algum resultado relevante de seus planejanentos.

O plancjador pode ser usidedo dentre ontras coisas, para definir a tarefia que a parte "reativa" irá realizar o para escollher quais são us comportamentos que deven estade ativos para a próxina tarefa.

\subsection{Arquiteturas Robóticas}

"Arrutelura robótica é a dischplina dedicada ao projeto de robôs alta-

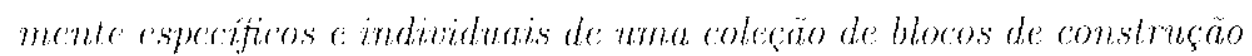
de softuare comuns." (Arkin. 1998)

Após cerolher um paradigna para a construçió de um sistema robótico, o próximo passo é escollher (ou desenvolver) una arquitetura.

Para farcilitar este processo, ó interessante conheerer diversas arculteturas pois

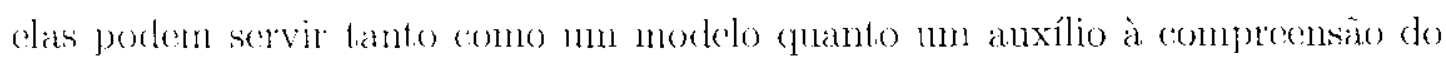
significade des parardigntans.

A seguir serãu apresentados exemplos de arruitecuras robóticas de cada um dos tres paradigmas descritos anteriomente (Murphy, 2000).

\subsubsection{Nested Hierarchical Controller (Paradigma Hierárquico)}

O NHC (Nested Hierarthical Controler) ten nitidancme separadas as primitivas SENTIR, P'LA.VE, AR e AGIR. Primeiramente, o robô collo informacõés de seu ambiente eas integra en um modelo de mundo gue porte conter também um 
conhecimento a priori sobre o ambientc. Após a criação ou atualização do modelo de mundo, o robó pode então planejar. O plancjanento no NHC ć dividido cm três módulos, o planejador da missão, o navegador e o piloto. O planejador (la missão pode receber uma missáo do operador do robó. ou criar una para si próprio. Essas missoes tem um alto nível de abstração, como por cxomplo: "pegar uma caixa na sala ao lado". É funcão do plancjador da missão expressar as missôs de forma que os módulos inferiores a ele entendam. O navegador recebe essa missão e traça um caminho do robô ató a mota composto de uma sćrie de segmentos de reta que ele passa ao piloto, un de cada ver. O piloto por sua vez recebe um segmento e determina quais ações ele deve realizar para alcançar a mota o as passa ao controlador de baixo nível, que as traduz em sinalis de controle.

O interessante desta arquitetura é a decomposição do plancjamonto. No caso de obstáculos entrarem no (aminho do rohô. não é necessário refazer o plancjamento todo. Após o controlador de baixo nível ter enviado sinais aos atuadores. o robô lê novamente as medidas de sens sensores a ar adaliza sen modelo de munclo. Lima vez que o robô já tem un plano, não é necessário executar nẹn o planejador da missão e nem o navegador. O piloto pode acessar dirctamente o modelo de mundo para descobrir se o robó se desvion do sen caminho (caso isto ocorra ele gerará novos comandos ao controlador do baixo nível), se de atingin o fim do scgmento do caminho passado pelo piloto (neste caso ele receberá un novo scegmento do navegador). on se ele encontrou um obstáculo, fazendo con que o piloto passe o controle an navegador o ynal por sua ver irá calcular un novo conjunto de segmentos que contornem o problema.

O problema desta decomposiçấ é que ela só é adeculada para tarefas de navegação, não fazendo muito sentido para onliras tarefas.

\subsubsection{Subsumption (Paradigma Reativo)}

As diferenças entro as diversas arquiteturas do paradigma reativo extão principalmente na forma cono organizam e combinam sexses comportamentes independentes para gerar seu comportamento geral.

Na arquitetura Subsumption (Arkin, 1998). os comportamentos são organizados em camadas. A combinação deles é feita de duas maneiras: por inibição ou por sueressão. Na inibiçăo, o comportamento inibidor substitui a saída do inibido. Na supressão. o comportamento supressor substitui a entrada do suprimido pela saída do supressor. Na Figura 2.4 na página opostat todas a sombinaçós säo do tipo inibidor. A seguir, é demonstrado um exemplo do que esta configuraça faz.

O comportamento geral fará com que o robò permaneça vagando até cue eucontre um obstáculo, quando então o comportanento "Evitando" iniliráa "Va- 


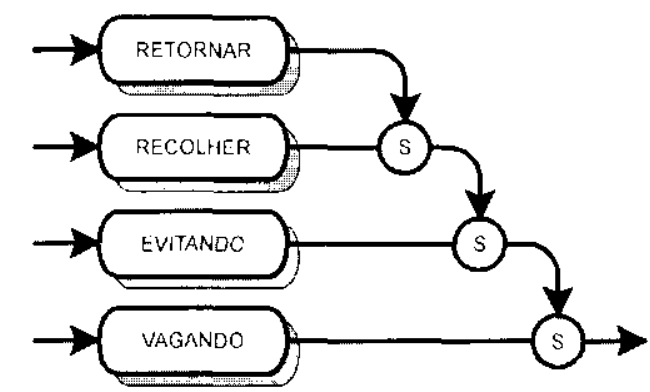

Figura 2.4: Exemplo da Arquiteura Subsumption

gande" " "vitará que "o robó bata em un obstáculo. Quando não houver mais olstáculus. "Vagando" voltará a ter o controle. So o comportamento "Recolher" sentir un objeto determinalo, de inibirá os comportanentos "Evitando" e "Vagande" o recolherá o objoto. Assim que o comportancuto "Retornar" sentir que" o robó tem un objeto, de inibirá todos os outros e voliará ao ponto de partida. F́. importante obscrvar (nie neste caso. "Retornar" deve saber como desviar do ubjetos.

\subsubsection{Saphira (Paradigma Hibrido)}

Essa arquitetura híbrida explora três áreas chave, coordenação coerencia, o comunicasäo. Leva-so en consideraçăo o fato de clue um robô deve coordenar sens atudadores o sensores, mas também deve roordenar seus objetivos globais de longo prazo. Coerência. neste contexto, s a habilidade de manter modelos de mundo globais. E a comunicação é importante pois robós devem interagir com seres humanos e com outros robos.

A maior parte da arguitetura está concentrada no planejamento. Ela usia um tipo de planojador reativo chamado PRS-lite (Procedure Reasoning Systemlite). Este plancjador é capaz do receber comandos em linguagem natural o operacionalizá-los por moio de tarefas de navegazão e rotinas de percepcräo.

Tanto o planejannento quantos a execução dependem do LPS (Local Perceptual Space) (que ó un modelo de mundo global. A maior parte do processamento nesta arcuitentura ó devotado a manter este modelo fiel à realidade.

A parte reativa desta arquitetura consiste en comportamentos que recebem como entrada medidas de "sensores virtuajs" extraídas do modelo de numdo globial.

\subsection{Navegação}

Tarefas sofisticadas requerem que un robô móvel construa mapas e use-os para se deslexar (Kortenkanp et al., 1998). A navegacăo de robôs móveis á realizarda 
basicamente por meio de três tarefas: localização. mapcamonto e planejamento do trajetória, as quais säo dofinidas a soguir.

\subsubsection{Localização}

Para operar de forma autônoma, robòs móveis precisam saber onde se encontram. Localizacão (commmente referida por estimativa de posição on controle de posiçáo) é o processo de detemininar e manter o controle da posição de 1 mm robo móvel rolativo a sen ambiente. Localizaçăo precisa é um requisito chave para a navegação em ambientes de larga escala, particularmente quando modolos globais são usados. como malpas, descnhos, descriçoes topológicas e modelos CAD) (Thrmin, 1998a).

Atualmente, os sistemas de robos móvcis de sucesso utilizam localizaçào (Borenstein et al., 1996: Kortenkamp et al., 1998). Ocasionalmente, localizacán tem sido referida como o problema fundamental para dar capacidades autonomas a robôs móveis (Cox and Wilfong, 1990).

() tópico de localização de robôs móveis será tratado com maior profundidade no Cappítulo 3.

\subsubsection{Mapeamento}

O mapeamento consiste na taufa de criar mon modelo do ambiende do robo por meio da integração de diversas leituras de seus semsores. O principal problema (1) mapoamento está no ruído o no crro introduzidos por seus sensores. Se o robo pudesse sempre saber corretamente sua localizaçăo e seus sensores fossem livres de ruído, a tarefa de mapermento seria trivial. Porém, neste ponto, entrames em 1 mo "deadlock" pois para realizar localização é necessário 110 mapa e para criar un mapa cinecessírio saber a posição do robô.

o processo de construça de mapas pode ser considerado como dois tópicos distintos. O robo tem que interpretar as leituras do sous semsores do forma a fazer

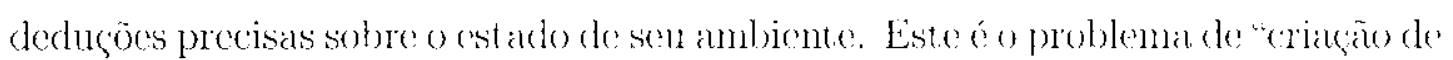
majas". Fle tem que escolher pontos de vista de modo que as medidas dos sensores

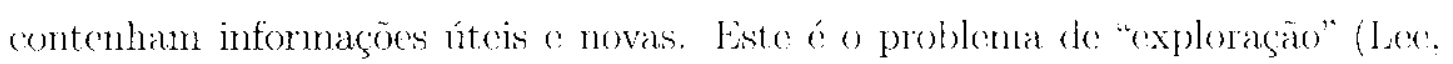
$\left.1996^{\circ}\right)$.

\subsubsection{Planejamento de Trajetória}

o problema do planejamento dr trajotória consiste em dados a posicäro atual do robò e sua meta, descobrir qual é o melhor camiulo até a meta. Além disso, deve-se garantir que. durante o descheamonto do robô em direcãa a meta, o robó irá desviar de possíveis obstácules najo previstos. As questós sobre o 
planejanento de trajetória serão discutidas no Capítulo 5.

\subsection{Considerações Finais}

Neste (apót nlo. foi feita uma revisão do vários conceitos que são indispensáveis a qualquer pesquisador que se interesse pela área $1 /$ hobolics. Os temas abordat dos aqui visan clar a base teórica necessária para a compromsäo dos próximes (a)pilulus.

() ir conceitos apresentados neste capítulo foram ntilizados na implementacaio

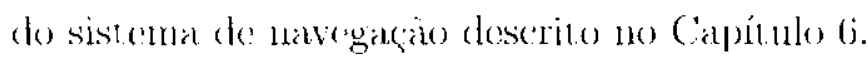





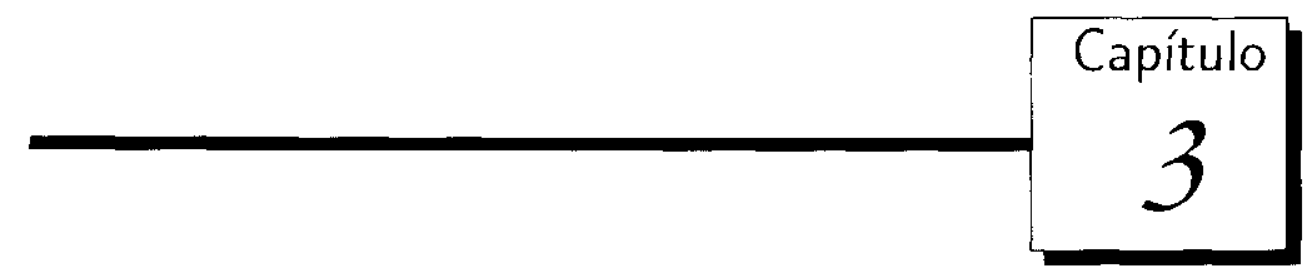

\section{Localização de Robôs Móveis}

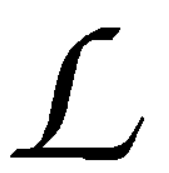

ocalização de Robôs Móveis, on simplesmente localização, é una tarefa que consiste en estimar a posição de un robô on seu ambiemu por mecio de informaçoes de seus sensores. Para isso. o robo deve tere a priori, um mapa do ambionte. o gual pode see comstruído automaticamente (pelo

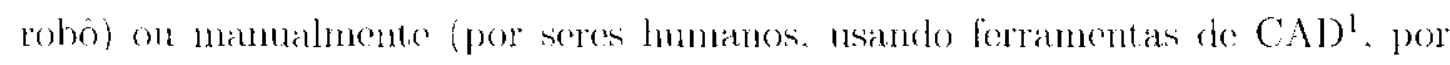
(xemplo).

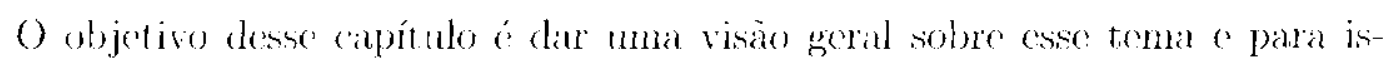
so foi organizado da segunine forma. Na Segano 3.1. o problema de localizaçio será dividido em categorias que ajudam a identificar o grau de abrangência de subs diforentes abordagens. Na Seção 3.2 na página 17 será apresentado uma

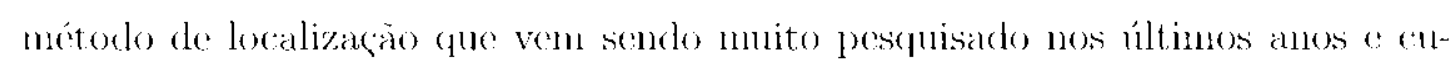
jos resuldados tem se mostrado muito satisfatórios. demominarlo Localizacão de Markov. Esse método foi desenvolvido inicialmente para ambicntes estáticos (na Seçào 3.1 .2 na próxima página serão descritos os ambientos estáticos a dinâmicos). Va Segáo 3.2.2 na página 21. será descrila a extensão desse método para ambiemes dinânices segundo a abordagem de Fox a al. (1998a). Por fim, serão feitas algumas consideraçoes sobre o capítulo.

\subsection{Categorias do Problema de Localização}

Existem várias abordagens cnure os métodos que resolven o problema de localizacão. Ena possível categorizaça as divide om (juatro dimensões: 1)locais ou globais: 2)para ambientos cstáticos ou dinâmicos: 3)ativas ou passivas: 4)um único robô ou múltiplos robôs (Thrum et al., 2000b). A seguir, as diferenças entre elas serao brevemente deseritias.

IFerramenta de projeto aluxiliado por computador 


\subsubsection{Métodos Locais Versus Globais}

As abordagens locais para o problema de localização exigem cule se tenha a posição inicial exata do robô a priori, pois clas somente sâo capazes de compensar os erros odométricos para manter coerente a informaçăo da localizaçáo do robó. On seja elas não conseguem rocuperar a posição do robô se ela for perdida devido à fallias.

As abordagens globais são mais robustas. Elas podem estimar a posição de um robô mesmo sem nenhuma informação a priori sobore sta localização. Ontra vanlagem das abordagens globais é a sua capacidade de se recuperar de falhas. Algumas podem até mesmo tratar un tipo especial de fatha conhecido como o "problema do robô seqüestrado", no qual o robó é retirado de seu local o posicionaclo em un outro sem que ele scja informado sobre esta manobra. Fste problema

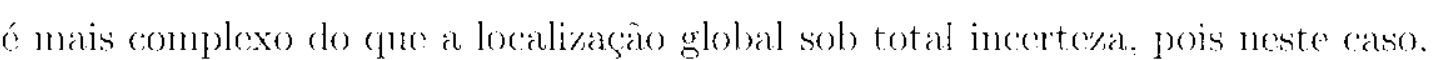
ao invés de nâa ter informaçoes sobre sua posição. ele possui uma informação mônèl.

\subsubsection{Ambientes Estáticos Versus Dinâmicos}

Lim ambiente estático ó acuacle em que o único objeto que se nove é o robô.

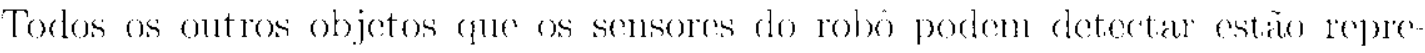
scntados no mapa. En contraste. os ambientes dinânicos podem possuir vários objotos móveis e não presentes no mapa.

A maioria dos métodos de localizaçäo pode lidar apenas com ambientes estáticos, ou ambientes com poucos elementos dinâmicos, os quais são tratados como rúdo. Porém, existem abordagons, como a proposta por (Fox et al. 1998a). que usam filtros para eliminar as leituras de sensores que possuan alta probabilidade.

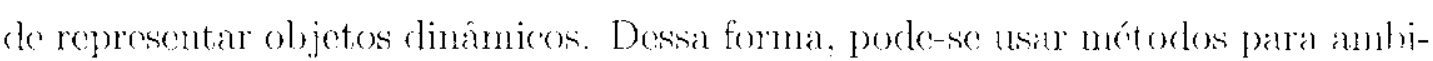
entes estáticos, mosmo en locais altamente populosos como musens e bibliotecas. O funcionamento destes filtros será descrito na Seçäo 3.2 .2 na página 21.

\subsubsection{Métodos Passivos Versus Ativos}

A localização passiva tratáa exclusivanente da estimativa da posiçào do robò baseando-se on um fluxo de dados provenientes de semsores. Nesta abordagem. a movinentação do robo e a diregäa de seus sensores näo podem ser controladas pela tarefa de localização. Em mótodos ativos, a rotina de estimativa de posição tenu o controle total on parcial do robo provendo una oportunidade de melhorar

${ }^{2}$ erro odométrico é um erro cansado por imperfoçöes mechnicas que fazem com que sensores

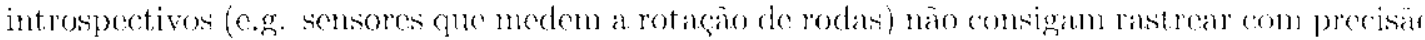
ats distancias percorridas por un robo (Everett, 1995). 
a eficoncia e a robustez da localizarão. As principais questós cm aborto das

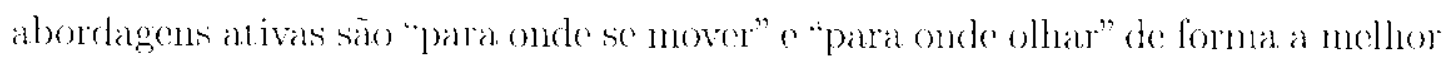
locatizale orobo (Fox ot al. 1998b).

\subsubsection{Um Único Robô Versus Múltiplos Robôs}

A abordagem mais commmente usada á a que envolve un único robô. Ela 6 conveniente, pois lodos os dados sáo coletados en uma ninica plataforma a näu

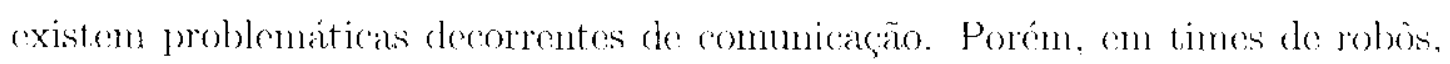
os mótodos de localizacão que não ignoram o fato de existirem múltiplos robôs oferecem a vantagem de que o conhecimento de un robô pode ser usado para influenciad a crença de outro. Por exemplo, um rolo X que sabe apenats que se encontra próxinno a unna porta possul várias hipóteses solore sua posiçán (cada hipótese correspondo a $11 m$ lugar próximo a lama porta). So X for detectado por outro robô $Y$ que sabe exatamente sua própria posição. X poclerá elinimar as talsas hipóteses baseando-se em infonmaçoes fornecielas por $\mathrm{Y}$.

\subsection{Localização de Markov}

Localizarazo de Markov é un método probabilístice. Ele mantém múltiplas lipóteses sobre a posição do robô. Cada hipótese possui um peso associado cue é um fator probabilístico numérico. A idéia principal é calcular una distribuição de probabilidades sobre todos os possiveis locais do ambiente.

Vesta seyão, scrá descrito o algoritmo básico desse: método (Fox et al., 1998a) que tem sido aplicido com muito sucesso em diversos trabalhos (Simmons ot al. 1997; Fox et al. 1999; Thrun et al., 2000a; Olson, 2000).

Seja $l=\langle x, y, \theta\rangle$ uma posicão no espaço de estados, no qual $x$ e $y$ são coordenadas cartesianas do robô e $\theta$ é a orientaço do mesmo. A distribuiçäo Brel(l)

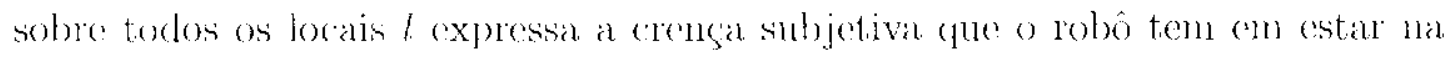

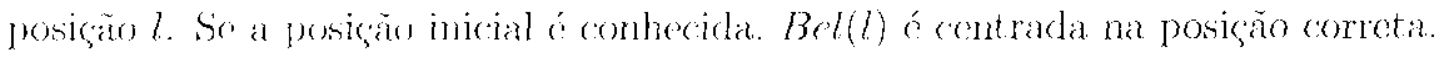
(aso contrário, ela f uniformemente distribuida para reftetir essa incerteza. Assinn cue o robô inicia sua operação, Bel(l) é refinada do modo incromental.

A Localizarão de Markov aplica dois modelos probabilisticos diferentes para

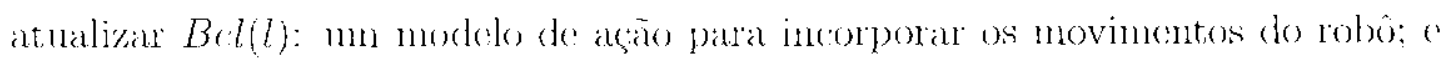
um nodelo perceptual para atudizar a crencä baseando-so na entrada sensorial.

A movimentagão do robó é modelada pela probabilidade condicional $p\left(l \mid l^{\prime}, a\right)$ que especitica a probibilidade de que uma aça a, quando excoutada em $l^{\prime}$, leve o robo para 1 . Bell) e entào afualizada de acordo com a fómula geral proveniente 
do domínio das cadeias do Markov, dada por:

$$
\operatorname{Bel}(l) \longleftarrow \sum_{l^{\prime}} p\left(l \mid l^{\prime}, a\right) \cdot \operatorname{Bel}\left(l^{\prime}\right)
$$

O termo $p\left(l \mid l^{\prime}, a\right)$ representia um modelo da cinemática do robô. Na implementação proposta por Fox et al. (1998a), foi assumido (que os erros de odometria são normalmente distribuídos.

As leituras dos sensores são integradas de acordo com uma fómunla de atualização Bayesiana. Soja s uma leitura de sensor e $p(s \mid l)$ a probabilidade do se perceber s dado que o robô está na posição l, então Bell(l) é atualizada de acordo com a regra:

$$
B e l(l)-\alpha p(s \mid l) B c l(l)
$$

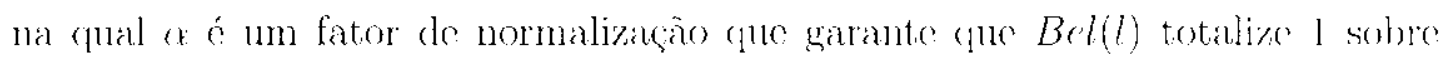
todo $l$.

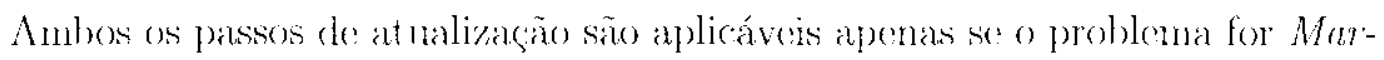
kioviano, ou seja, se as leituras de sensores passadas forem condicionalmente independentes de leituras futuras dada a localizaçăo do robó. Desse modo, a hipótese de Markov assume que o mundo é estático. Apesar de na prática essa abordagem ter sido aplicada até mosmo em ambicntes que continham pessoas o que desta forma violavam a hipótese de Markov. os experimentos reportados em (Fox ct al., 1998a) mostram que ela não se adequa bem a ambientes densamonte povoados.

Uma das formas de resolver esse problema consiste na aplicaçâo de filtros gue sclecionam quais leituras dos sensores serão utilizadas efetivamente na localizacầ. O intuitó é elininar as leituras influenciadas por objetos dinânicos. Na Seção 3.2 .2 na página 21 serão descritos os dois filtros propostos por fox ct al. (1998a).

\subsubsection{Questões de Implementação}

Fxistem diversas formas de se inplementar a técnica de Localização de Mar-

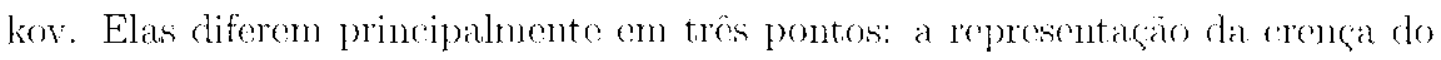
robò; nos procedimentos de atualização da crença; e nos modelos probabilísticos de ação e percepç̃o.

A seguir scrão descritas, de forma extremanente sucinta, algumas implementaçòes. Serào focalizados principalmente os aspectos de representanäo o atualizatçào da crença, scm explicar cm detalhe seu funcionamento. 
Além disso, possui uma alta precisào quando usando granularidade fina. Porém, de possui altos requisitos de memória a tempo de processannento.

\section{Localização Monte Carlo}

O algoritmo de Monte Carlo (Algoritmo 3.1), representa a crença Bel(s) por um conjunto de amostras s associadass a um fator numérico de importância $p$. Esse fator indica a probabilidade da amostra ser relevante para a determinação da posição do robô. A crença inicial é obtida gerando-se aleatoriamente $\mathrm{N}$ amostras da distribuição prévia $P\left(s_{0}\right)$, e atribuindo-se o fator de importúncia uniforme $\mathrm{N}^{-1}$ para cada amostra.

lecturas de sensors o o açòes a são processadas em pares. Monte Carlo constrói uma nova crença repetindo a seguinte seqüencia de "suposiçóes": primeiro. um estarlo aleatório s é gerado a partir da crença atual. sob consideraçăo dos fatores de importância. Para alquele estados. Monte Carlo supoè um novo estardo $s^{\prime}$ de acordo com o modelo de ação $P\left(s^{\prime}, a, s, m\right)$ no qual $m$ contém os dados do mapa. O fator de importancia para esse novo estado $s^{\prime}$ recebe um valor proporcional à consistencia perceptual desse estado, como medido por $P(o \mid s, m)$. A noval amostra, juntamente con seu fator de importâucia, ó memorizada o o laço básice (repetido. A geração de amostras é finalizada quando a soma total dos fatores de importanncia exceder um limite $p_{\max }$, ou quando o próximo par $\langle o, a\rangle$ chega. Finalmente, os fatores de injortância são nomalizados o o método de Montc Carlo retorna o novo conjunto de amostras definido eomo a crença corrente.

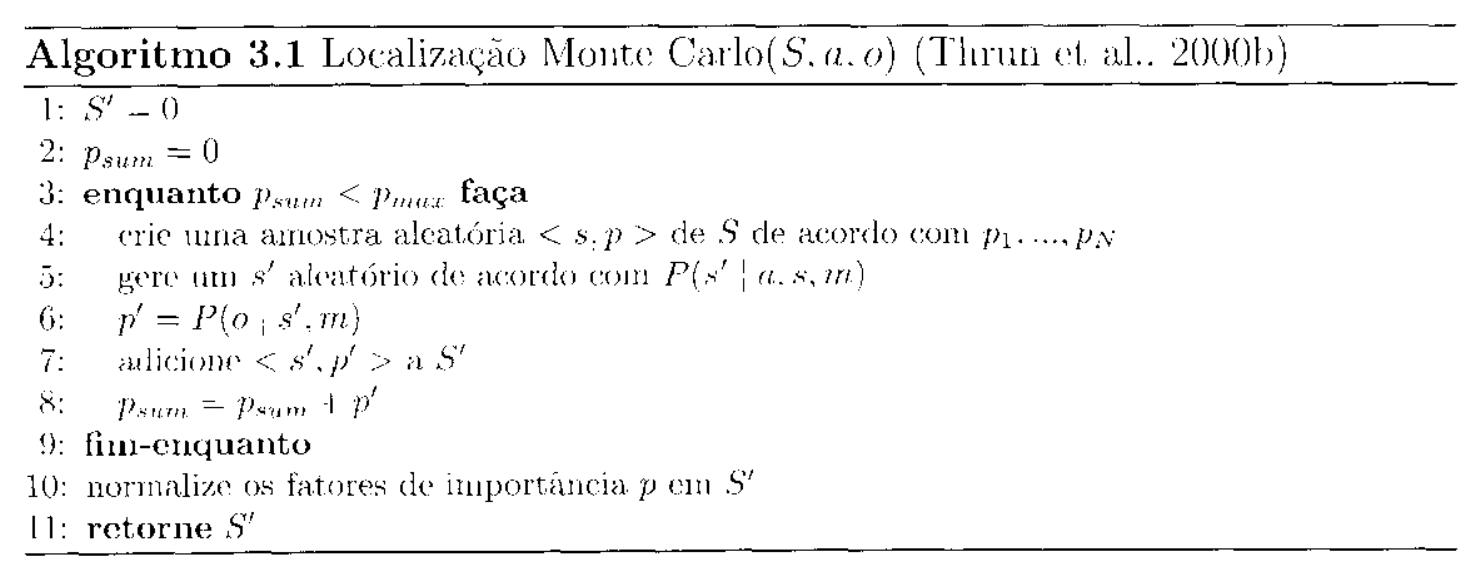

Lima desvantagem desse método ó a do que ele possui uma tendencia a descartar hipoteses corretas e às vezes näo se recupera de fallas do localizaciou global (náo resolvendes o problema do robo sexuestrado). Felizmentes: essa deficiencia pode ser facilnente resolvida adicionando amostras aleatórias. matematicamente justificadas assumindo que o robó pode ser sequestrado com una pequenar probabilidade. 


\section{Localização por Filtros de Kalman}

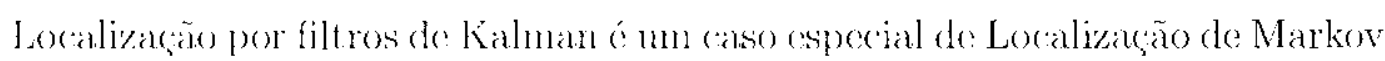
que usa Ganssianas para representar a crença do robô o as cquaçoes de atualização dos filtros de Kalman.

A seguir falaremos apenas das vantagens e desvantagens desta técnica. As explacoes de atualizacro. juntamente com uma explicacäo sobre filtros de Kalman podem ser encontradas em (Thrm et al., 2000b).

A vantagem deste mótodo é a sla extrema eficiencia, podendo estiman rapoidamente a posição do robô. Porém, ela possui uma série de desvantagens listadas a seguir:

- necessidade de modelos de erro gaussianos o que restringe sua aplicação a problemalo espercílicosi.

- rcalizar ajernas o rast reamento de posição. não podendo exerntar a localizasão global a nem resolver o problema do robô sequestrado.

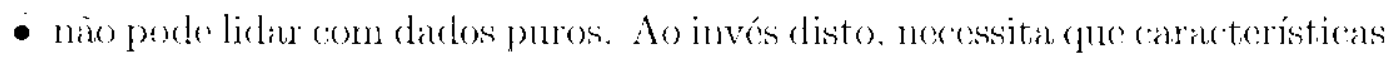
apropriadas sejam extrádas.

\section{Localização Baseada em Grids}

Euse tipo de lecalização representa o espaço de estudos por uma divisão métrica de um mapa. Divide-se o mapa cm um plano quadriculado no qual cada. célula representa uma possível posiçãe do robô.

A representaçäo pode ter gramularidade fina on grossia. A granulariclaule diz respeito ao tamanho das células usadas no mapa. Yesse caso, há uma troca entro desmpenho e precisão. Encquanto a granularidade fina (células pecuenass) ó mais precisa. a grossa é mais conômica en temos de memória o tempo de processador.

Dependendo do tambuho do anbiente e da granularidade, essa abordagem se toma intratável polos processidores atulais. Para resolver este problema, existe

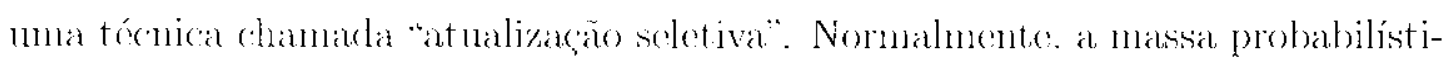
ca. reside em um aparentemente pequeno número de células, pois a grande maioria possui probabilidade 0 ou próxima de 0. Baseando-se nesta propriedade, a "at.ualização seletiva" atualiza apenas as células que possuem uma alta probabilidade associadia. Esta estratcigia anmenta a eficiencia en várias ordens de magnitude com un impacto mínimo na confiabilidade.

Sumarizando as vantagens o desvantagens: pode se dizer que esse método écapaz de realizar localização global o trata o problema do robô secuestrado. 
Fin contraparticla, ele possui uma scrie: de vantagens sobre os outros métodos

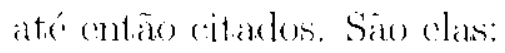

- Extremamente eficiente pois a computaça tem seu foco em regiónes de alta probabilidarde.

- Mais fácil de implementar do que as abordagems de localizagão de Majkov alternativas.

- Robusto a ruídos a a mudianças que afetenu a disponibilidade de recursos computacionais.

- Capacidarle de se adaptar aos recursos. Adaptando o mímero de amostras. a qualidaule da solucão depende dos recursos computacionajs disponíveis. Ao trocar o processiador do robò por um mais rápido, Monte Carlo pode utilizar estes recursos adicionais som alteraçoes no código fonte.

\subsubsection{Filtros}

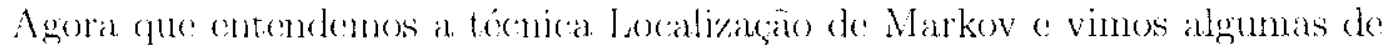
slas implementaçoes, podemos explicar como ala pode ser usada con ambientes dinânicos sem vjolar a hipótese de Markov. Como mencionado anteriormente, Fox el al. (1998a) propos dois filtros prara eliminar leituras indesejáveis causadas por objetes dinandeos. A seguir esses dois filtros serao descritos.

\section{Filtro de Entropia}

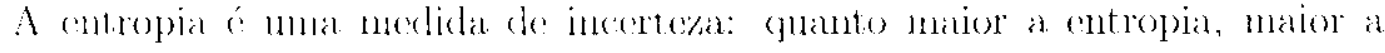
incerteza do robo sobre sua posiçán. A entropia. $H(b)$ de uma distribuição sobre lé definida por:

$$
H(l)=\sum_{l} \operatorname{Br} l(l) \log B d(l)
$$

() filtro de entropia mede a mudanga molativa do entropia cansada pela ineor-

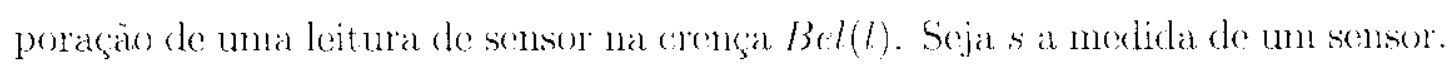

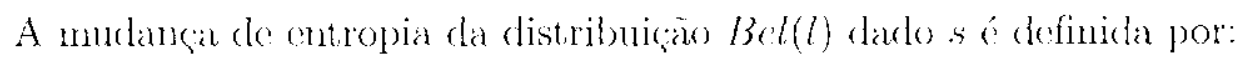

$$
\Delta H(l \mid s)=H(l)-H(l \mid s)
$$

Juna mudancáa negativa de ontropia indica que após a incorporação de s. o

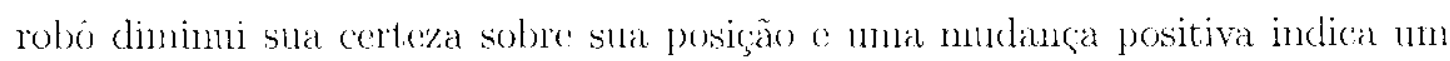
alumento) Ha (chte\%, 


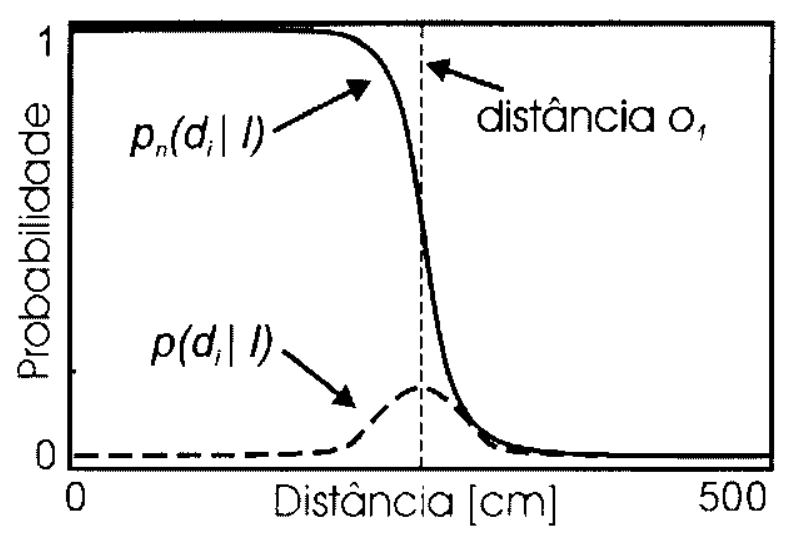

Figura 3.1: Probabilidade $p_{n}\left(d_{i} \mid l\right)$ de que a leitura $s_{i}$ seja mais curta do que o esperado. (Fox et al. 1998a)

Tin exemplo de heurística a ser usada con o filtro de contropia fo o de utilizar apenas medidas s para as quais $\Delta H(l \mid s) \geq 0$. Destal formal. esse filturo torna a percepcuín do robó altanente seletiva pois considerará aponas medidas que confirmem a crença atııal.

Uma grande vantagem do filtro de entropia é a de poder ser usado com qualsucr tipo de sensor. Porém, de causa um efeito colateral. O tempo gisto para que o robô se recupore de um erro de localização (e.g. o problema do robó se(puestrado) é clevado, pois o filtro irá climinar a maioria das medicoces comrotats. já que elas não confirmam a crença atual que ó incorreta.

\section{Filtro de Novidade}

O filtro de novidade; ao contrário do de entropia, é projetado espercificamente para sensores de proximidade. Este filtro selecionat as loituras dos sensores de acordo com un grau do "novidade". Cnna medida s ć considemada "nova" para o robô, se ela for refletida por um obstáculo näo representado no mapa. Em leituras de proximidade, este caso só pode ser detectado se a medida for mais curta do que o esperado.

O filtro então remove as medidas de proximiclade que possuírem probabilidade maior do que $\lambda$ de serem mais curtas do que o esperado. Suponha que $d_{1}, \ldots, d_{n}$ é um conjunto discreto de possíveis distancias medidas por un sensor de proxinidade. Seja $p\left(d_{j} l\right)$ a probabilidade de se medir $d_{j}$ se o sensor detertar o próximo ubstáculo no mapa. A probabilidade de $d_{i}$ ser mais curta do que o (esperado $p_{n}\left(d_{i} \mid l\right)$ co calculadia pela seguinte equagäo:

$$
p_{n}\left(d_{i} \mid l\right)=1.0-\sum_{j \leq i} p\left(d_{j} \mid l\right)
$$


A distribuiçăo que descreve a medida coperada juntumente com a distribuição para sensomes de proximidade (linha tratejada) dada a distancia on para o próxino obstáculo, é ilustrada na Figura 3.1 na página anterior.

Para lidar com situaģoes nas quais năo se sabe a posição do robô com absoluta certeza, a média de todos os possíveis locais é usada para obter a probabilidade

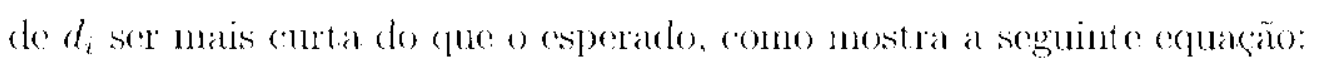

$$
p_{n}\left(d_{i}\right)=\sum_{i} p_{n}\left(d_{i} \mid l\right) B e l(l)
$$

O método de selega do filtro do novidade consiste en exchur todas as medidas $d$ que tenham $p_{n}(d)>\lambda$.

A diferença entre os dois filtros está no fato de que o filtro de entropia sempre lenta confirmar a crenca atual do robó (estando ela correta on nào) enquanto o

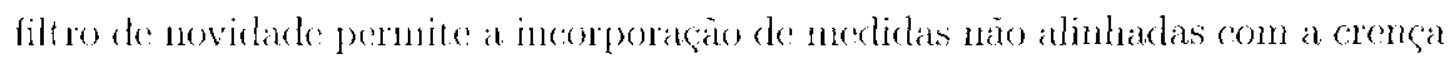
atual (especialmente medidas muito longas).

\subsection{Considerações Finais}

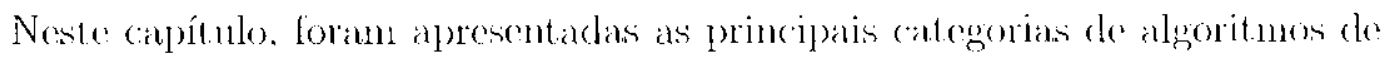

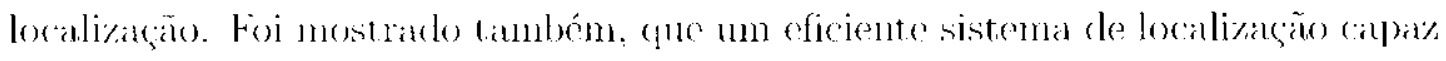

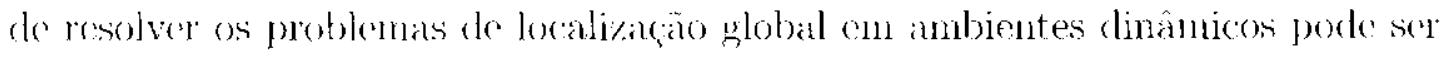
implementado usando a técnica Localização de . Markove en conjunto com filtros de entropia ou de novidade. Apesar disso, os filtros naro säo essenciais se o ambiente for moderadamente dinamico. Em nossos experimentos, não empregamos nenhum dos filtros e mesmo em anubientes dinâmicos a performance da localização não se degradou significativamente. 



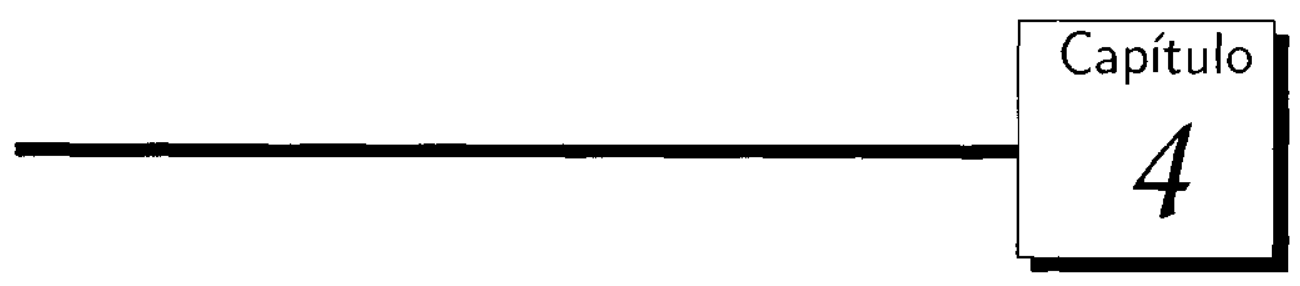

Mapeamento

omo já mencionado anteriormente. pàla que un robò possa se locomover de forna anionoma cm anbientes não estruturarlos é necessário que ele saiba a cada instante sua localização. Isso pode ser alcançado utilizando os métodos descritos no Capítulo 3. l’orém, esses métodos requerem a existência de um mapa do ambiente que pode ser dificil de se construir manualnonte caso não haja um disponivel. Nesse capítulo scrá exposto um nótodo para realizar o mapeanento antomát ico de ambientes, a partir dos darlos providos pelos sensores do robô.

O processo de mapeamento de ambientes pode ser dividido em duas tarefas: síntese do mapa e exploração. A sintese do mapa ó uma tarefa passiva do ponto de vista do controle. Fle consiste en dadas as observacoes do ambiente, construir uma represontagào de mesmo. A exploragão é um processo ativo que visa controlar o robo de forma que cle "visualize" com seus sensores todas as partes do ambicinte.

Os mapas gerados por métodos de mapeanento automático possuem várias vantagens sobre a confecção mannal e sobre a aquisição por modelos CAD' on plantas de projetos arquitetônicos:

- Nudangar no ambiente: () anbiente de robó muda com o tempo. Deste modo, torna-se difícil manter um mapa preciso manualmente.

- Relacionando o Mapa aos Sensores: F́ difícil para un usuário predizer quais aracterísticas do mundo scrão facilmente reconheciveis pelos sensores do robo. Quando á utilizado un sensor de varredura de distancias baseado em raio laser, fependendo da aliura en que de for instalado no robô, o mapa

Modelos gerades com ferranentas de projeto anxiliado por computador 
que representa as características identificávcis por cle poderá ser diferente para cadal altura. Un mapa provido pelo usuário pode então ser de ponco valor.

- Nível de: Iotalhe: Para alguns propósitos, o nível de detalhe requerido pode ser mais alto do que o que pode ser obtido por meio de um projeto arguitetonico. Por exemplo, num projeto arcputetonico pode estar especificado o local de uma mesa, já no mapa gerado automaticamente, se o sensor do robô está abaixo da altura da mesa, cada um dos pós da mesa serão representados.

Nas seguintes Seçoes, serão descritos os tipos de manats commente ntilizades em métodos automáticos de mapeamento e o mótodo utilizado neste trabalho.

\subsection{Tipos de Mapas}

Pesquisas recentes produziram dois paradigmas fundannentais para a modelagem de ambientes fechados para robòs: o métrico (grid-based)e o topológico. Abordagens métricas, como as propostas por Borenstein and Koren (1991) entro outros: representam ambientes por mallas de células igualmente espaçaklas contro si. Cada célula pode indicar a presença de um obstáculo na região correspondente no ambiente. Abordagens topológicas, representann os ambiente por grafos. (os nós nestes grafos correspondem a situaçòes, lugares ou marcos distintos. Eles são conectados por arcos se existir un canimho direto entre eles (Thrun, 1998b).

Ambas abordagens possuem pontos fortes e fracos. As métricas permitem uma fácil construçăo e manutenção de mapas em ambientes amplos. Elas climinam as ambiguidades de locais distintos baseando-se na posição geométrica do robô. A posiçăo do robó ó estimada incrementalnente, bascando-se nas informaçós odometricas providas pelas leituras dos sensores. Desse modo, as abordagens métricas normalmente usam um número ilinitado de leituras de sensores para determinar a posição do robô. Assumindo gue a posição do robo pode ser rastrcada precisamente, diferentes posiçooss, para as cuais as medidas dos sensores se parecem, tên slats ambigundades naturalmente clininadas. Lecais fisicamente próximos são reconhecidos como tal. até mesmo quando as medirlas dos sensores difereme (que ó o caso dos ambientes dinàmices onde. por exemplos. humanos podem bloquear os sensores).

Este não é o caso das alordagens topológicass. Abordagens topológicans doterminam a posição do robô relativa ao modelo principalnente bascando-se em marcos. Por exemplo, se o robo atravessa dois lugares que se parecem. aborrlagens topológicas freqüentemente tem dificuldade on deleminar se estes locais 
são distintos on näo. Alén disso. conno a entrada sensorial normamente depende fortemente do ponto de vista do robo as abordagens topológieas tendem a fallat no recouhecimento de locais geometricamente próximos, mesmo on ambientes estáticos. tormando difícil a construção de mapas grandes. particularmente se a informaça semsorial é altamente ambígua.

l’or outro lado, as abordagens métricas sofrem por sua morme complexiclale: de: espaço e tempo, A resolução da malha devem ser firla o suficiente para capturar cada detalhe importante do mundo. A vantagen chave da representaça topológica é a sua capacidade de compactação. A resolucão dos mapas topológicos correspondem diretanemte a complexidade do andsente. A capacielade

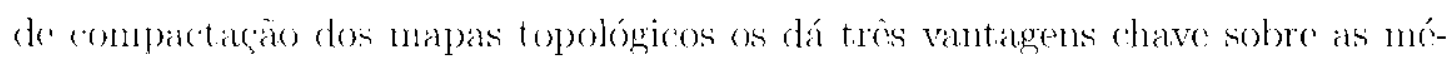
tricas: (a) permitem realizar um planejamento rápido, (b) facilitan a interface com planejartores simbólicos e (c) provém interfaces mais naturais para instruçoes humanas (como: "vá para a sala A"). Já que as aborelagens topológicas nommalmente nào requerem a exata deteminação da posicáo geométrica do robo, elas freqüntemente se recuperam melhor de crros odométricos (erros que devem ser constantemente monitorados e compensados em abordagens métricas).

foe (1996) rlassiticon os tipes de mapas da seguine mancira:

- Mapas de Locais Reconhecíveis: O mapa consiste em uma lista de locais que podem ser reconhecidos pelo robo de forma confiável. Nenhuma relasão geométrica pode ser recuperada.

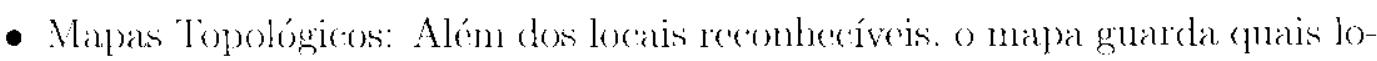
cais são conectarlos por caminlos atravessáveis. Conectividade entro locais visitados pode ser recuperada.

- Mapas Métrico-Topológicos: Este temo é usado para mapas nos quais distância e angulo sajo adjecionados à descriçáo do caminho. Informaçoes mótricas sobre os caminhos podem ser recuperadas.

- Mapas Totalmente Métricos: Os locais des objelos são especificados em um sistema de coordemadas fixo. Infomnaçon métricas podem ser rexmperadas sobre quaisquer objetos no mapa.

Nesse trabalho, os mapas utilizados são totalnente métricos e serão descritos lla próxima sceriono. 


\subsection{Occupancy Grid}

Nessa seção, é descrito $u m$ método para o mapeamento de ambientes que usa uma representação probabilística e reticulada da informaçăo espacial chamadir Occupancy Grid. Esso método trata do problema da construção de mapas consistentes a partir de semsores gue apresentan rúcto o outras incertezas.

() Occupancy Gridé é un campo aleatório multidimensional cue formece cstimativas dos estados das células cm $m$ empaço reticulado. A representação dos mapas no Occupancy Grid ó uma matriz de ocupação multidimonsional (tipicamente 21) ou 3I) que mapeia o espaço on células, onde cada célula armazena uma estimativa probabilística de seu estado. Os cistades possíveis são ocipado ou livre (Elfes. 1989).

As costimativas do estado das células säo obtidas por meio da interpretana a das leituras de distanncias usando modelos probabilísticos dos sensores. Cin procedimento de estimativa Bayesiano permite a atualizaçäo incremental do Ocenpaney Grid usando beituras realizadas por vários sensores sobre múltiplos pontos de vista.

A variável de estado associada a umáa cólula $m_{\langle x, y\rangle}$ do Occupancy Grid ó definida como uma variável aleatória discreta com dois sestados, ocuparia o varia. denotialas OCC o E.MP. Dessa forma o Occupancy Grid corresponde a um campo aleatório do estados discretos e binários. Una vez que os estados das células são exclusivos e exaustivos, $P\left(m_{\langle r, y\rangle}-O C()-P\left(m_{\langle x, y\rangle} \ldots l M P\right)=1\right.$.

Para interpretar os dados sensoriais (medidas de distânciass), é arado um modelo probabilístico do sensisor $P^{P}\left(m_{\langle x, y\rangle} \mid e^{(t)}, s^{(t)}\right)$ (que define a probabilidade de uma célula $m_{\langle x, y\rangle}$ estar ocupada dados a observação do sensor o $o^{(t)}$ e a posiçäo do robó $s^{(t)}$. Esse modelo é utilizade em $u m$ procedimente de estimativa Bayesiano para

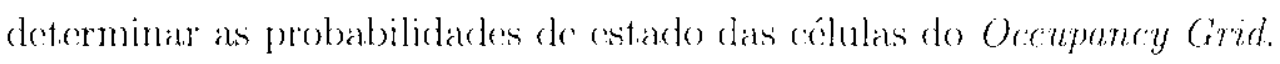

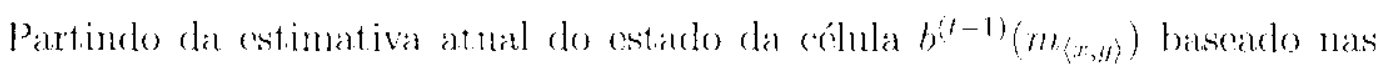
observaçoes anteriores e dada uma nova observaça o ${ }^{(t)}$, a estimativa atualizada 6 dada por:

$$
\begin{aligned}
& b^{(t)}\left(m_{\langle r y\rangle}\right)= \\
& 1-\left(1+\frac{P\left(m_{\langle x, y\rangle} \mid \gamma^{(t)}, s^{(t)}\right)}{1-P\left(m_{\langle x, y\rangle} \mid o^{(l)}, s^{(l)}\right)} \frac{1-P\left(m_{\langle x, y)}\right)}{P\left(m_{\{x, y\rangle}\right)} \frac{b^{(l \cdot 1)}\left(m_{\langle x, y\rangle}\right)}{1-b^{(t \cdot 1)}\left(m_{\langle x, y\rangle}\right)}\right)^{1}
\end{aligned}
$$

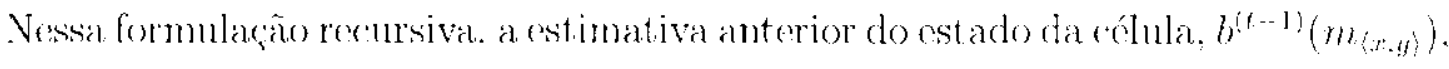
serve como priori é obtida diretamente do Occupancy Grid. Essa nova estimativa 


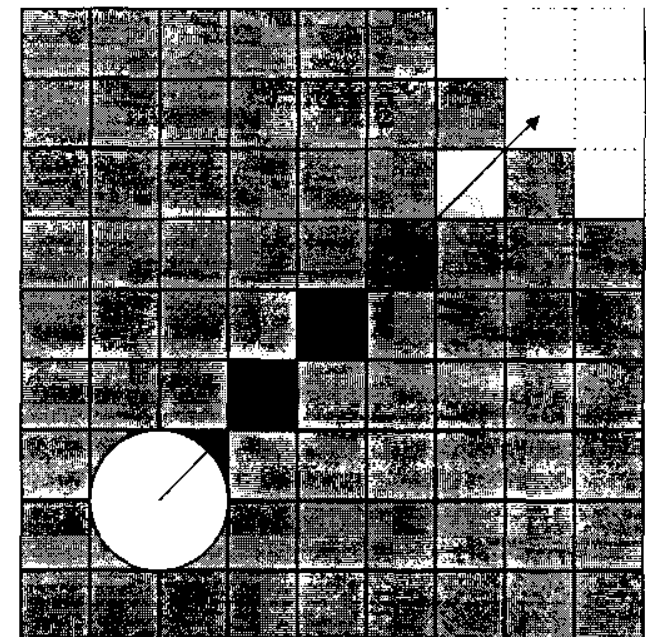

Figura 4.1: Aturalização do mapa por un dos raios projetados pelo sensor. O círculo representa o robô. A seta indica o raio. A parte en cinza claro no canto superior direito do miapa é um obstáaculo.

é cottào armazenata no mapa.

Esse procedimento é realizado para cada célula clue esteja no alcance perceptual do sensor. Enı nossa implement ação, utilizamos um sensor (SICK PJS) que faz uso de um raio laser para realizar suas mediçôes. Como o raio laser é linear, nós atualizamos todas as células entre o ponto onde o raio encontrou um obstáculo até o ponto onte está o robô utilizando o algoritmo de conversão matricial de segnentos de retal de Bresenhlam (Foley et al. 1995) para determinar quais as cólulas atualizar. A Figura 4.1 descreve a atualização do mapa referente a 110 único raio laser. Note que as cólulas que o raio laser intercepta são atualizadas. As células em branco possuem alta probabilidade de estarem ocupadas e as em prete possuem alta probabilidade de estaren varias. Note cues segundo o modelo probabilistico do sensor. as células mais próximas do ponto onde o raio laser identificou um obstáculo possuem probabilidades mais altas de ocupação do que as próximas ao roló.

Existe um (asce especial em que csse procedimento não ś utilizado. Quando o robô está sobre a cólula, $b^{(t)}\left(m_{(x, y)}\right)=0$ diretamentes pois temos certeza de que ela cstá livre.

Dessa forma obtém-se um mapa que representa as probabilidades de ocupaçāo de carla célula. Enn nossa implementaçäo, foi utilizado o mapa sem maiores trantsformagoess porém, on algunas aplicagooses, ó necessário um malpa determinístico, que pode ser obtido utilizando estimadores ótimos, como a regra de decisão máximo a posteriori (MAP) para atribuir estados discretos para as células (ocupada, vazia ou desconhecido). 


\subsection{Occupancy Grid com Localização Monte Carlo}

O método Occupancy Grid por si só não alcança bons resultados em ambientes

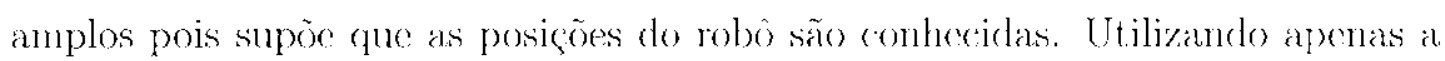
informação odométrica do robô. o crro acumulado a medida que o robô se move ó suficiente para que o método falhe em modelar corretamente o ambiente, não sendo capaz de apresentar uma representação útil para a tarefa de navegação como pode ser verificado na Figura 7.2 na página 48. Para que se possa tirar proveito de Occupancy Grids nessas condiçoes devemos integrá-lo a algum método de localização.

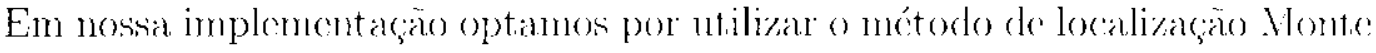
Carlo. A abordagem para a integração se baseia na observação de que o sensor utilizado (SICK PLS) permite o mapeamento de parte do ambiente con o robo parado em uma única varredura. Desse modo, nossa abordagem intercala ciclos de mapeamento com ciclos de localização.

Inicialmente mapeia-se os primeiros sete metros do campo de "visão" imediatamente a frente do robô. Então, a cada metro que ele se desloca on a cada 30 graus de rotaçăo ele se localiza com base nesse trecho de mapa gerado. Como descrito na Seção 3.2.1 na página 20, o método do localização Monte Carlo mantém un conjunto de amostras associadas a um fator de importancia referente a sua consistencia pereptual. Com base na posição da amostra de major fator de importancicia e a atual leitura do PLS, o mapa é atualizando seguiudo a regra de atualizaçăo da Equaçào 4.1 na página 28. Esse processo é repetidlo até que se construa uma representação apropriada de todo o ambiente, sendo que o robó deve "visualizan" no mínimo uma ver todas as partes do ambiente om seu campo de visão de 180 graus. O Algoritmo 4.1 na página oposta descreve o laco de comandos que define esses passos.

Para mapear nossos corredores, a estratégia adotada foi a de levar o robô até o final de cada corredor, virar 180 granus e voltar. Na Figura 4.2 na próxima páginil. é mostrado um exemplo de exploração de ambientes para o mapeamento. Em

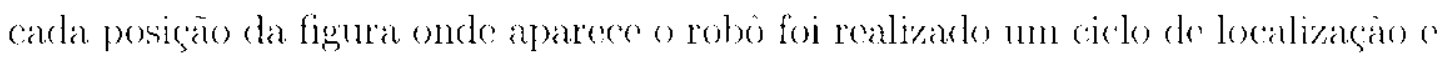
mapeamento. Na prática, pode se utilizar qualquer comportamento de navegação para o mapeamento contanto que passe por todos os lugares do ambiente pelo menos uma vez. A estratégia ótima consiste em sempre que possível deslocar o robó en linha retal o passiar o menor múmero de vezes pelo mesino lugar fazende com que ele visualize todas as partes do ambiente pelo menos uma vez. Desse mode, o mialpa é construido minimizando os crres de odometria que oceorem principalmente duratute as rotaçoes do robo. 

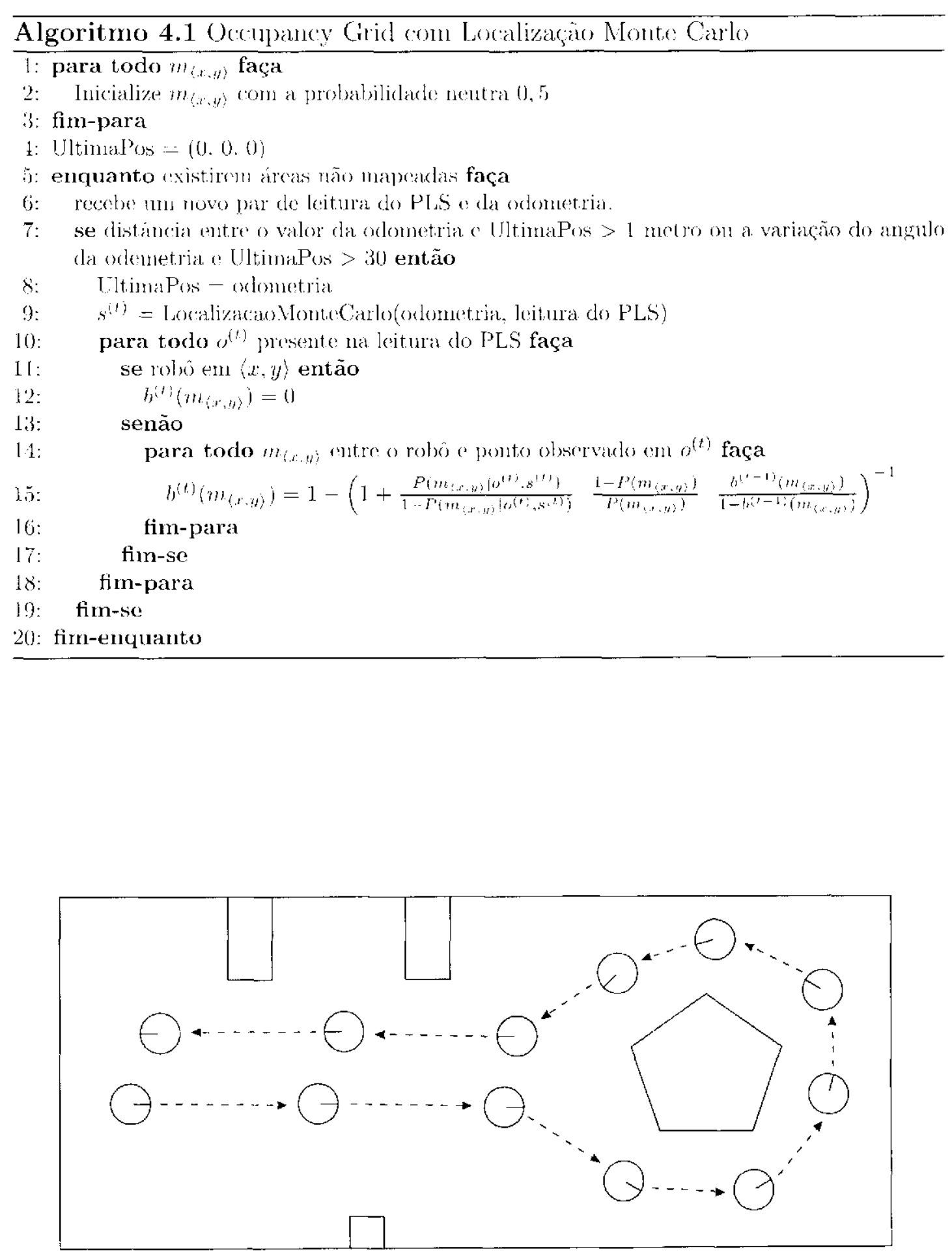

Figura 4.2: Estratégia de Mapeamento: Os círculos representam o robó nas posiçós onde honve realização de un ciclo de localização e mapeanento. 


\subsection{Considerações Finais}

Nesse capítulo, o mapeamento automático de ambientes foi descrito e um método probabilístico para a realização dessa tarefa foi apresentado. Nossa abordagem para sua implenentaçào consiste na integração do método de mapeamento Occupancy Grid com o método de localização Monte Carlo.

Essa abordagen pode sor utilizada em tempo raal e produz mapas consistentes com o ambiente. Resultados detalhados da utilização dessa abordagem encontrant-se no Caprítulo 7. 


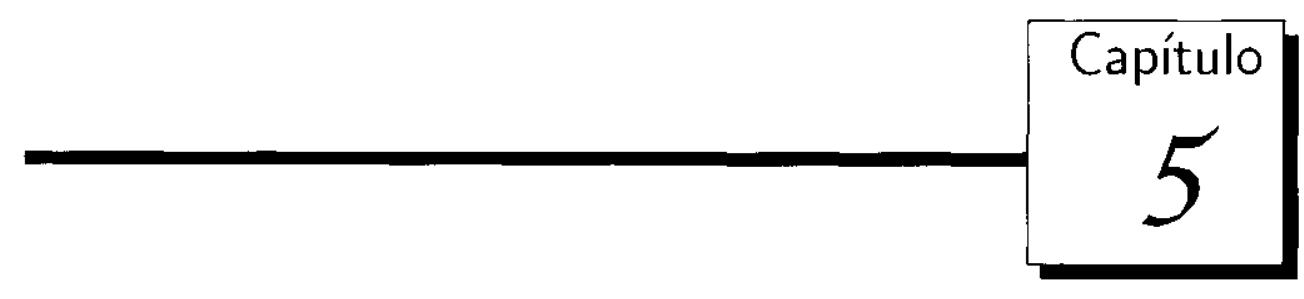

\section{Planejamento de Trajetória}

$\mathcal{R}$

obôs móveis anônomos devem saber como trilhar seu caminho recebendo como dados apenas sla meta o as informaçöes de seus sensores. Pate problema consiste en descobrir sua posicao no mundo. Isso meta um robo móvel tambén precisa decidir quais comandos enviar a seus atuadores para que de se desloxue de maneira segura e pelo melhor caminho possivel.

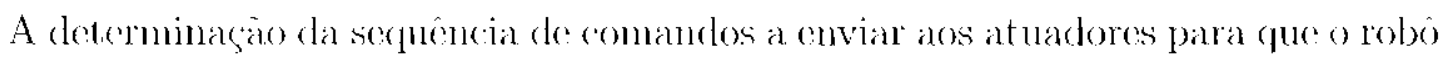
atiuja sua meta. desviando de obstáculos e possivelmente objetivando otimizar o custo é realizada pelo planejamonto de trajetória.

Os métodos pará o planejamento de trajetória estáo divididos en duas cattegorias: qualitativos (ou topológicos) a quantitanos (ou métricos) (Murphy. $2000)$.

\section{Planejamento de Trajetória Topológico}

Este tipo de metodo é o mais adequado para um robó baseaclo no paradigma reativo pois neste lipo de planejanento as trajotórias são expressas na forma de. diretivas do tipo "siga este corredor, vire a esquerda no final do corredor e entre na sogunda sala à dircita”. Mesmo sem ter um mapa, existe informação suficientc para a navegação. uma vez que o robo sabe o que c um corredor, un final de corrector e mmat salia.

A navegagão tepológica depende da presenga de marcos. Lin mareo é composto de uma ou mais características perceptualmente distinguiveis de um objeto ou local de interessis. O plano resultanté é normalmente una rota que indica por quais marcos o robo deve passar. 


\section{Planejamento de Trajetória Métrico}

Ao contrário do planejamento topológico, o plancjanento métrico geralmente favorece técnicas que produzem uma trajetória ótima. Já o planejamento topológico parece se contentar em produzir una rota com marcos identificáveis Outra diforença é que as trajetórias métricas são normalmente decompostas em submetas consistindo de pontos de verificacăano. Esses pontos de verificarano são normalmente uma posição fixa ou coordenada $(x, y)$.

Ctilizando o paradigma híbrido da robótica podenos rlividir o plancjamento de trajetória em uma parte deliberativa c ontra reativa. A parte deliberativa ó realizada normalmente por um planejador que é responsávol por determinar as submetas anteriormente mencionadas. A parte reativa, que nessa dissertaça chamaremos de controle de trajetória, controla o robô de modo a levá-lo de maneira segura. desviando de obstáculos. cntre us pontos defiuddos nas subunetas.

A seguir, duas abordagens para o controle de trajetória serão apresentadas.

\subsection{Campos Potenciais}

A abordagem de Campos Potenciais segue o paradigma reativo. Portanto, cla comanda o robô utilizando uma combinação de comportamentos que tem sua saída representada na forma de vetores. Estes são integrados pola soma velorial de suas saídas, resultando cm comportamentos muito interessantes pois não estäo cobertos por nenhum dos comportamentos individuais.

Em navegaçăo, a abordagem de Campos Potenciais tem sido utilizada para realizar o desvio de obstáculos ao mesmo tempo em que o robô persegue uma metia Iloward et al. (2002): Rimon and Koditschck (1992); Barraquand and Latombe (1991). Para isso, as leituras do sensores que detectam obstáculos no ambiente. são modelados como vetores de repulsão. fiazendo com que o robó tenda a se: manter longe de obstáculos. Fsses vetores de repulsão tem tananho inversamen-

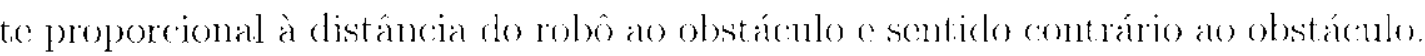
A meta, é modelada como $11 \mathrm{~m}$ vetor de atração que tem tamanho constante e sentido em direção à meta. A soma deste vetores produz un vetor resultante que indica a direçăo a seguir e seu tamanho indica a velocidade a ser utilizada.

Na Figura 5.1 na página oposta pode ser visto lum exemplo da aplicação de Campos Potenciais a problema de navegação de robôs móveis. Nessa figura. o circulo representa o robô, os fuadrados são obstáculos e o pentágono representa a meta a ser seguida pelo robô. Os vetores representados por setas de linhas pontilhadas são os vetores de repulsão. A seta de linha tracejada ó o vetor resultante da soma vetorial dos vetores de repulsão. A seta de linha pontilhada e tracejada 


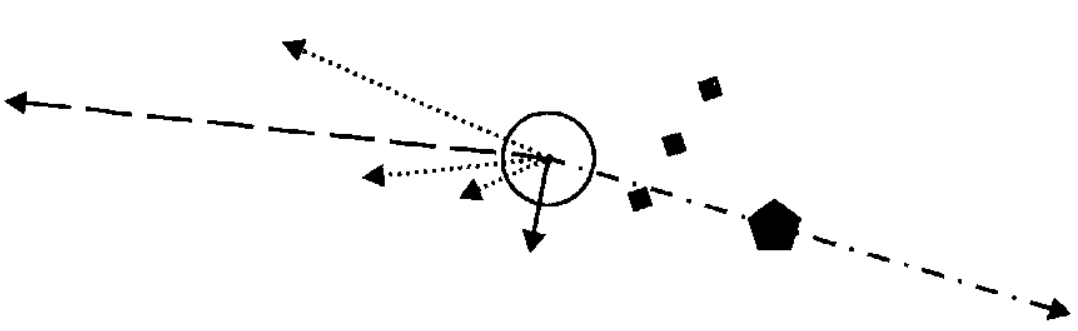

Figura 5.1: Exemplo de Campos Potenciais

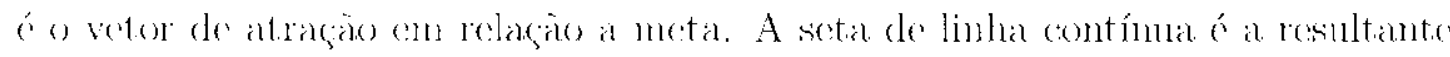

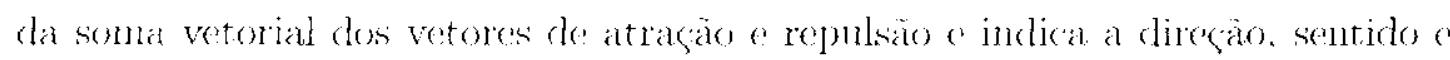
velocidade que o robô deve ter nosse instante para chegar a meta.

Essa abordagem prodn\% una navegaçào suave em que o robô se afasta dos obstáculos com antecedencia e com una intemsidade proporcional a distância entre o robô e os obstáculos. Pormu, cla possui algumas limitaçōes. Em algumas siluaçoes. a soma do todos os vetores de repulsão o o vetor de atração resultará enu zoro e o robo irá parar. Isso é nomalnonte resolvido pelo próprio ruido

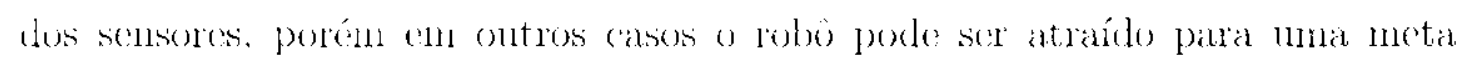
que se encontra at rás de uma parede e o robò náo consegue contomá-la para encontralr a meta. Essses (asos são normalmente classificados como problemas de mínimos locais. Outro problema é encontrado na navegaçăo em corredores estreitos, existem casos en que a abordagem de Campos Potenciais irá apresentar 1 mo trajetória instrivel e poderá até mesmo fazer com que o robò bata com uma parede. Esses o outros problemas, assim como mais informaçôes sobre Campos Potenciais, sãos encontrados em (Koren and Borenstcin, 1991).

\subsection{Vector Field Histogram}

Para realizar o controle de trajetória foi utilizado o métode VFH alue foi desenvolvido por (Borenstein and Koren, 1991) para contornar os problemas identificados no amplamente utilizado método de Campos Potenciais.

Esse métudo mantém un mapa nuctrico probabilístion simplificado bascado em mallhas (parecido com o Occupancy Grid) porém ao invés de valores reais entre 0 e 1 representando a probabilidade de ocupação da célula, ele utiliza valores int ciros de 0 a 5 . Esse mapa também difere de um Occupancy Grid pela forma como é obtido, pois para operar com a rapidez necessária para que o robo desvie de obstáculos em velocidades altas. a manutemão do mapa não pode gastar muito tempo de processumento. Dessa forma, ele é obtido por uma técnica chamada amostragen rápicla. oncle cada célula inicia en 0 o é incrementada em 1 a cada ve\% que um scmsor detecta um obstáculo em slla posiçäo até que ela alcance o 
valor máximo 5. quando então não mudará mais de valor.

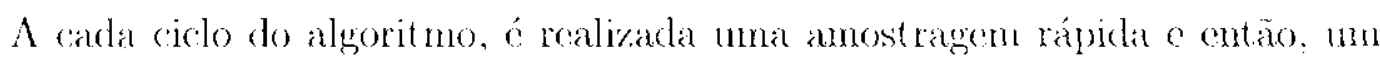
histograma polar ć criado, dividindo as regiões em torno do robo em $k$ setores e: medindo a densidade de ocmpação de cada setor. Para isso, năo é utilizado o mapa inteiro e sim uma janela do mapa chamada de "regiào ativa" cujo centro é o robô. Cada cólula cej da região ativa é analisada e são atribuídos dois valores a cada uma sua diregão em relação ao centro do véculo dada por

$$
\theta_{i . j}=\operatorname{tian}^{-1} \frac{y_{j} \cdot y_{0}}{x_{i}-x_{0}}
$$

c sua magnitude dada por

$$
m_{i, j}=(c, i, j)^{2}\left[a-b d_{i, j}\right]
$$

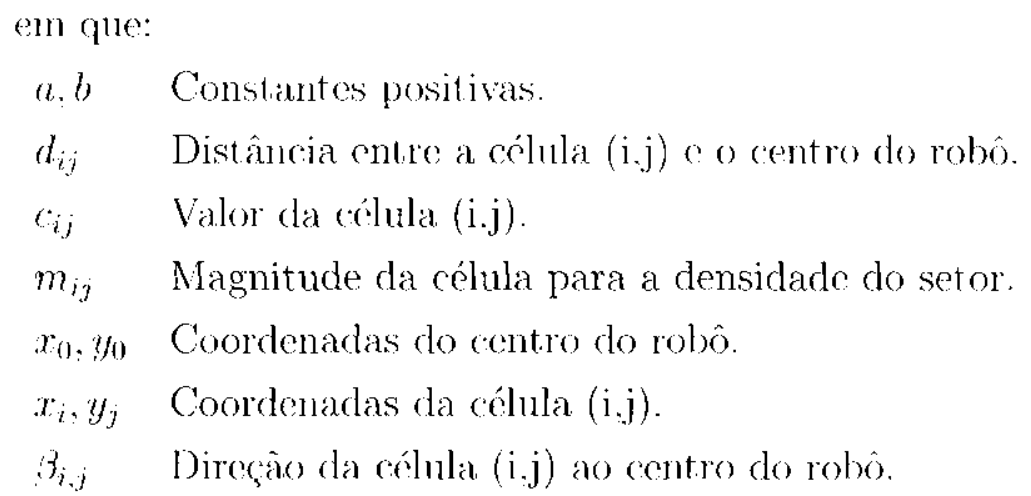

Para setores com largura angular $\alpha$, a correspondencia entre as cólulas alivas c seu setor ć dada por

$$
k=I N T(3 / \alpha)
$$

ra densidade de ocmpacăo he para cada setor he do histograma polan é calculada por

$$
h_{k:}=\sum_{i, j} m_{i, j}
$$

Por fim, devido a natureza discreta do hislograma polar. una funcão de stavizacróo ó ntilizada para melhorar a saída do mesmo. definida por

$$
h_{k}^{\prime}-\frac{h_{k-1}+2 h_{k-1+1}-\ldots+l h_{k}+\ldots+2 h_{k+l-1}+h_{k+1}}{2 l+1}
$$

Com o histograma polar pronto, é nexessário determinar o angule $\Omega$ entre o robo e a meta. Então escolhe-se o setor $k$ referente ao ângulo mais próximo de $\Omega$ que tenha densidade de oeupacão monor do que numa ronstante pré-elefinida. o ângulo referente a esse setor determina a dircgào do robo. A volocidade de 
translação, pode ser determinada com hemrísticas en relaçào as densidades de ocupacăo póximas ao angulo referente ao $k$ escolhicho.

\subsection{Considerações Finais}

No presente projeno, foram tesladas una abordagem utilizando Campos Potenciais o nuna baseada no método VFH. Ambas possuem características e limitacous esperificas. Por exemplo. Campos Potenciais são inadequados para a navegaça on corredores estreitos pois apresenta instabilidades que podem causar até com que o robó bata em paredes. Essas limitaçoes são discutidas om Koron and Borenstoin (1991). () método VFH, apesar de resolver alguns dos problemas de Campos Potenciais, lambém possui os seus. Unta delas ocorre quando o robô encontra uma bifuxcação em que un corredor leva a um beco sem saída e outro leva até a mela. Nessa situaça o método muitas vezes opta pelo beco sem saida. Essas limitaçoes sáo discutidas e tratadas por Chrich and Borenstem (2000).

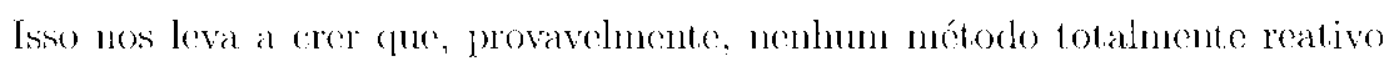
será capaz de resolver de forma completa os problemas de controle de trajetória. Cm planejamento en un nível maior de abstraça é necessário para definir submetas a serem seguidas pelos métodos reativos de modo a evitar caminhos problemáticos para o método cm uso. Tal planejamento deve ser adaptável on trmpo real. verificando o progresso da navegação e identificando problemas enfrontados pela parte reativa para então definir uma nova submeta que climine os problemas.

Vossa implementagano deixa esse planejamento a cargo do usuário do sistema. o qual define a priori as submetas necessárias para que o robô alcance sua meta. A maior falha desse método ć que. conno desejamos que nosso robô seja autônomo. não podemos inderferir durante a navegaçäo portanto, se algum problema não previsto na definigàn das submetas ocorrer. näo será possivel corrigi-lo. Desso modo, um de nossos trabalhos futuros consiste na implementacão de tal método de planejamento. 



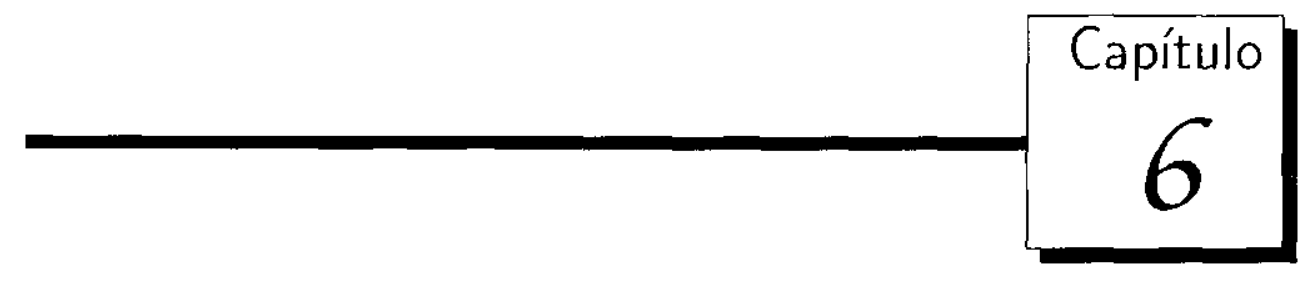

Desenvolvimento do Sistema

Nesse capítulo, o sistema é descrito cm termos de sua arquitetura e funcionalidades. Alén disso, algumas das dificuldades encontradas durante o dexenvolvimento săo comentadias.

O restante deste capitulo irá detalhar os componentes do sistena.

\subsection{Descrição do Sistema}

$\mathrm{O}$

sistema de navegarão proposto neste projeto foi implementado seguindo o paradigma híbrido (ver Seça 2.2.3 na página 8). Desta forma de possui tanto componentes reativos quanto deliberativos.

No nível de controle mais baixo. as tarefas do desvio de obstáculos e a nave-

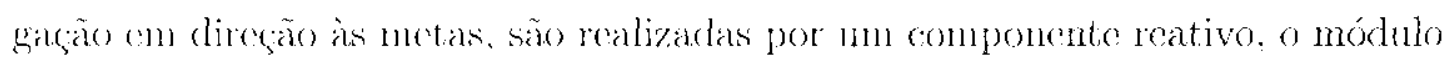
de navegaçào. (Is componentes deliberativos são responsáveis por criar modelos do ambiente e estimnar a posição do robô de modo a fornecer ao módulo de: navegagão una informagàn mais correta do que a obtirla diretamente dos sentrores. Na verdade, os componentes deliberativos atuam para o módulo de navegaçào (omo se fossem sensores virtuais. Os módulos de mapeamento e localização são os componentes deliberativos.

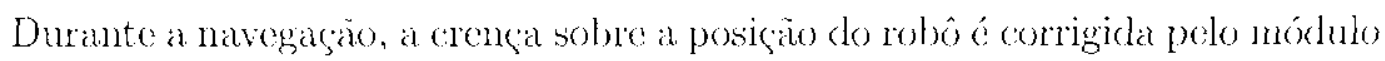
de localizacão permitindo gue as metas scjan alcançadas com precisão.

Antes ao início da operação de entrega de documentos, o sistenta explora o ambiente para que o módulo de mapeamento crie o mapa do ambiente no qual o robò irá operar.

A dinànicá do sistema durante sua excencão ó a seguinte. O usuário define pontos em 1111 maja pelos guais o robô deverá passar e pontos em que o robô devo parar. Então o módulo de navegação irá levar o robô de um ponto a outro desviando de obstáculos estáticos e dinâmicos, parando nos pontos detemuinados 


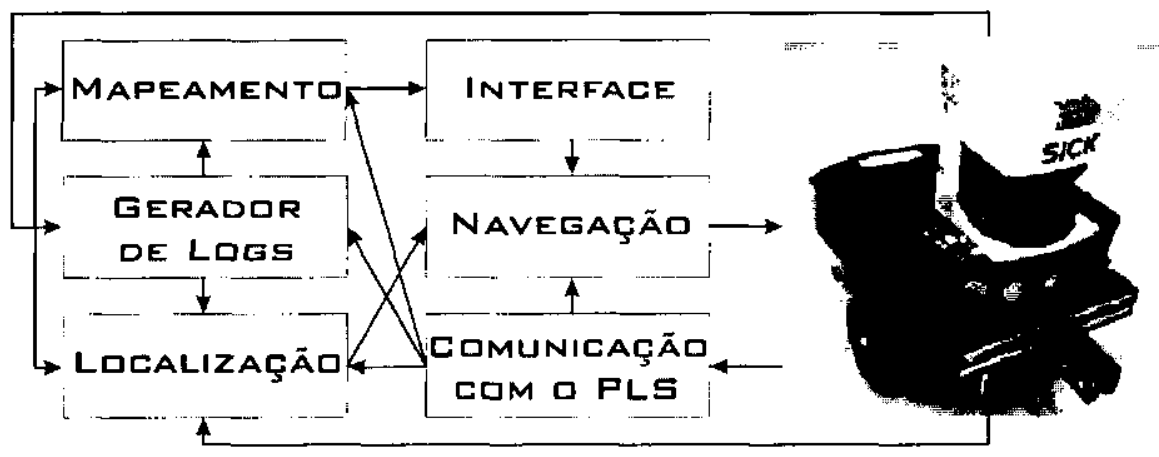

Figura (j.1: Arquitotura do Sistema

pelo uniánio. Os pontos pelos quais o robô deve passar mas não parar năo sĩo pontos de entrega de documentos. Fles estäo presentes para cue o usuário pessa 1.re un controle maior sobre a rota do robô afirn de evitar caminhos problemáticos como locais onde existem objetos estáticos abaixo da aluma mínina necessária para serem identificados polo PLS ou pontos onde existem mínimos locais e outras "armadilhas" as culais o método VFH ́́ suscectível.

Fissa abordagem será substitúda por uma mais robusta onde existe a figura de un módulo de planejamento (une está sendo implementado em um outro projeto do mostrado do grupo. Com base em um mapa topológico constrúdo sobre o mapa métrico a múltiples pares "origen o destino" esse módulo de planejamento irá definir uma rota ótina entre os portos pelos quais o robô deve parar levando en consideração diversas funçòes de avaliacão conno distância tolal a ser percorrida bempo de cespera de cada entrega probabilidade de problemas em uma determinada rota (c.g. ocorrencia de mínimos locais) e etc...

Una visão geral da arepuitchura do sistema pode ser vista na Figura 6.1. Nessa figura, as setas indicam o sentido da transferencia de dados contre os módulos.

A seguir, a Sção 6.1.1 descreverá os componentes do hardware e as segoces seguintes descreverão os componontes de software.

\subsubsection{Hardware Robótico}

O sistema foi implementado sobre a plataforma do robô Pionecr 1. mostrado na Figura 6.1. No início do projeto. esse robó não cra adecquado is nossas necestsidades. Sua fonte de percepcrio consistia om apenas 7 somares Polaroid fi500 ${ }^{1}$. Estes dispositivos são muito imprecisos e näo provecm dades wat islatórios para as tarefas de localização e mapcamento, indispensáveis para o projoto.

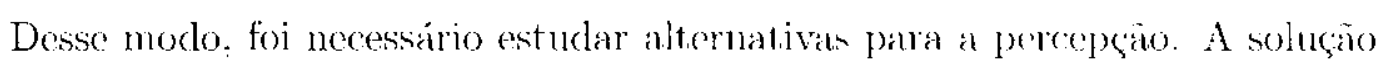
encontrada foi a aquisição o adapteação ao robô do um sensor donominado PIS (

\footnotetext{
'Dispositives que medem distâneias por reftexo de ondas ult ra-bonicas
} 
Proximity Laser Scanner). Este sensor é capaz de rastrear seu ambiente com un

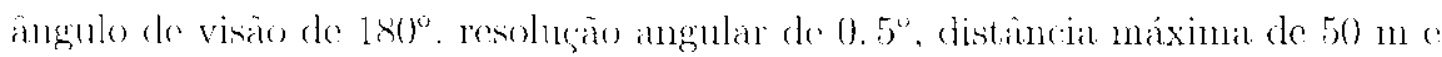
(rro de $131 \mathrm{~mm}$ jara distancias $\leq 4 \mathrm{~m}$

Durante a adaptacão, vários problemas foram identificados e resolvidos. Foi

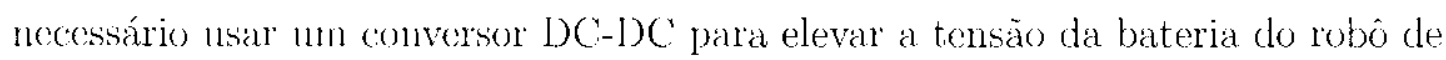
$12 \mathrm{~V}$ para $24 \mathrm{~V}$, pois o PLS opera neste nuvel de tensäo. Tante o robo como o PJs, devene ser ligados a um notebook (cuce faz o papel de controlador) através de uma porta serial, porém, o notebook dispunta de apenas mo porta desse tipo. Desso

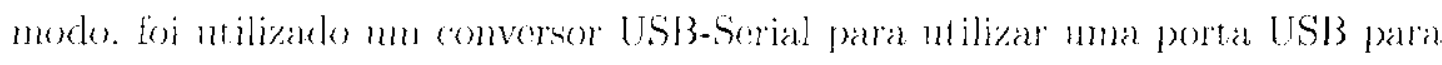
faver a conexaro do l’LS. Por fin. foi necessário desenvolver um prograna que: implementa o protocolo de comminaca do P'LS.

Além disso, una prateleira foi adaplada an robô para suportal os documentos a serem transportiados.

\subsubsection{Interface}

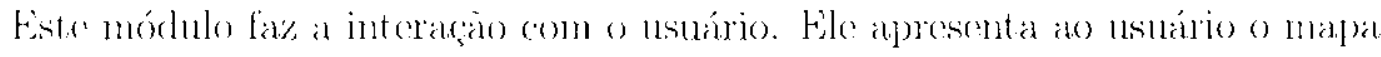
do ambiente no chlal o usuário poderá marcar os pontos pelos quais o robo deverá passar e pontos onde o robo deverá parar. Nos pontos onde o robo parar de deve esperar até que uma tecla seja pressionada on que un deterninado tempo limite:

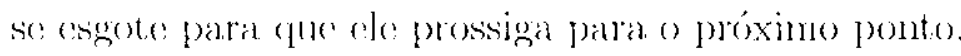

\subsubsection{Comunicação com PLS}

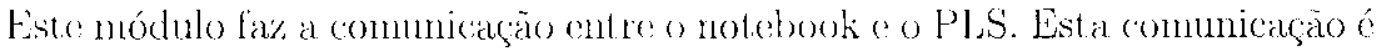

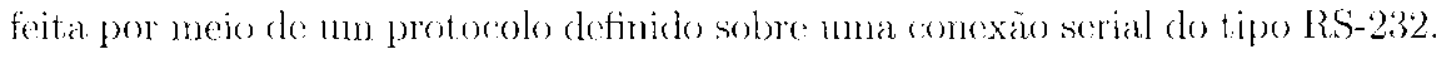
Através deste módulo, os outros módulos tem acesso às leituras das distâncias do ambjente.

\subsubsection{Gerador de Logs}

Este módulo gera un arequivo contondo registros das medidas do PLS, a datale

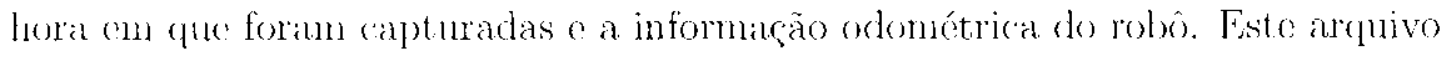
de loge é utilizado para realizar experimontos comparativos de mapeamento o localizaçàn em casos en que se deseja testar vários parâmetros dos algoritmos em condiçoes identicas, realizande vários experinnentos como o mesmo log.

\subsubsection{Localização}

Lisando o algoritmo de localizaşão Monte Carlo descrito no Capítulo 3, este módulo laz or rastreamento da posição do robô relativa a seu ambiente. 


\subsubsection{Ferramenta de Mapeamento}

Este módulo éo responsável por gerar mapas métricos de ambientes. A abordagem de mapeamento proposta nessa dissertação intechra o método de mapeamento Occupancy Cirid descrito na Segão 4.2 na págima 28 com o método Lo(alização Monto Carlo descrito na Seção 4.3 na página 30. Nessa abordagem, o

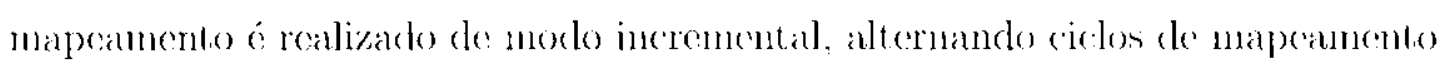
com ciclos de localizaçào.

Inicialmente o robó executa um riclo de mapeamento. gerando um pequeno trecho do mapa, co robô se desloca a uma distancia pequena determinadia. Então o robô cxecuta un ciclo de localizacäo e com base na amostra de maior consistência perceptual com o trecho de mapa previamente gerade. () mapa de atralizado incluindo mais um trecho. Então o robo se destoca mais uma vez e o cicto se repete continuasuente alé (que o ambicnte todo esteja mapeado.

\subsubsection{Navegação (Controle de Trajetória)}

Com base nos dados recebidos do PLS e da posição do robó fornecida pelo

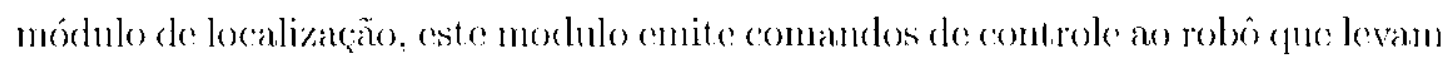
o mesmo áos pontos definidos pelo nsuário no módulo de interface destiando do obstácules utilizando o método VFH descrito na Segão 5,2 na página 35.

\subsection{Considerações Finais}

Esse sistema nầ contém um ńnico lhuxo do controle (thread). várias larefas sào executadas simultaneamente através de programação multithread. Fxistem trîs fluxos de controle sendo execulados simult aneanonte. Un doles o milizado

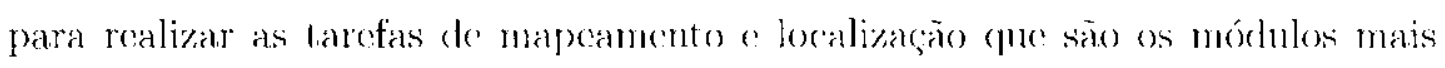
"pesados" cm lemos de consumo de CPU. Lim outro fluxo de controle separardó utilizado para realizar somente o controle de trajetória, una ve\% que csisi larefa é crítica e se não for excentada a tempo o robo pode bater em obstáculos. Por fime um terceiro fluxo de controle é o responsável pelas atividades de interface.

O desenvolvimento desse sistema nes apresenton vários desatios o as diversals dificuldades que enfrentanos foram renolvidas e isso facilitará a implementação de trabalhos futuros que se basciem nesse sistema. Dentre as dificuldades podemos

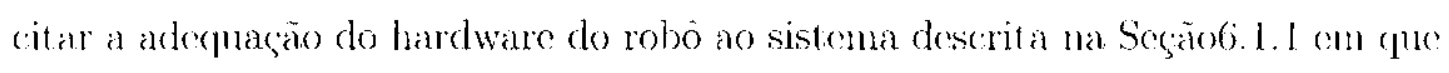

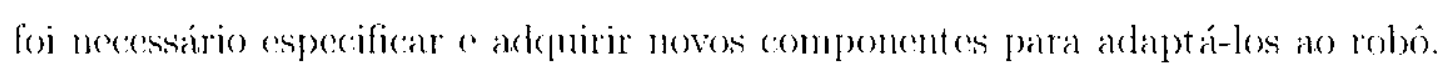
a implementaçào do protocolo de comminicacio com o PIS. enulre out ras.

Os módulos aqui deseritos, foram implementados seguindo o paradigma ori-

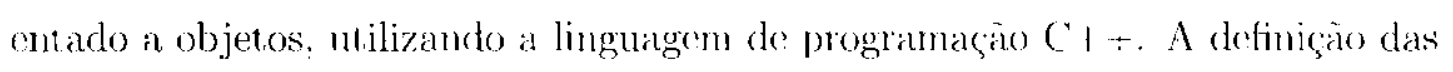


classes que implementam as funcionalidades de mapeamento, localizacão e controle do trajetória foi realizada visando obter alta coesaa funcional o baixo acoplanento de dados. Dessa forma, ssas funcionalidades possuem uma interface muito bem definida são separadas da interface e das peculiaridades do hardware robotice utilizado. Classes de interface foran projetadas espocificanneme para o sistema de entrega de documentos assim cono classes de controle foram feitas especificamento para o robo Pionere 1 e o semsor SlCK PLS. Dessa forma, os mótodos implementados são facilmente adaptáveis a outras aplicaçoes e outros robos.

No próxino (apótule, os resultados dos experinuentos ralizades utilizando o sistena de navegaçu descrito nesse capétulo serão apresentados. 



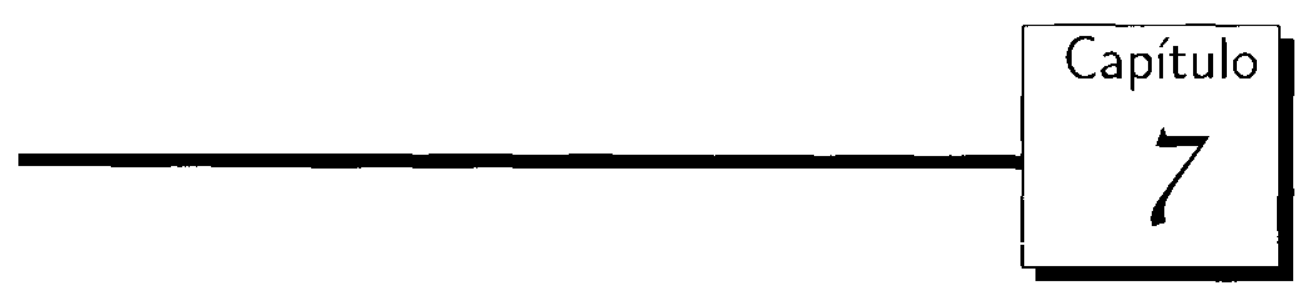

\section{Resultados}

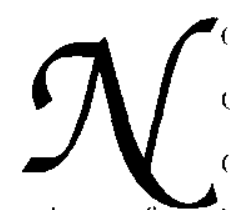

Sise capótulo são apresentados os resultados empíricos e mensuráveis obtidos durante o desenvolvimento desse trabalho. Serão apresentados os dados referentes a algumas métricas arlotadas para garantir o bon funcionamento do sistema. Os experimentos contemplan os mélodes de localizaçäo, malpsemento o controle de trajotória.

Pari comparar diforentes configuracón dos paranetros dos algoritmos em condicoses ienticas. alguns experimentos foran realizados posteriomente a exerução de un trajeto. com base em logs gerados durante a execucăo dos mesmos.

Os logs o os experimentos foram projetalos de tal forma que não exista diferenca entre a realizacáo dos experimentes durante a execução do trajeto e a realizargan posterior bascada em logs. Os logs consistem em ma seqüencia do pares compostos da leitura do sensor PLS e da informação odomótrica obtida no momento da leitura. Durante a gravaçào do log. o sistema é executado em rempo real normalmente a cada par é gravado no log no exato momento em cue o sistema faz as requisicoes do leitura de sensores rue necessita para realizar as tarefas de mapeamento e localização.

\subsection{Performance da Localização}

Vos experimentos ralizados com localização local a posição inicial foi fornecida), o robo pereorreu un total de 1500 metros (total de 10 exeencones). Em todos os casos, os dados são referentes a execuçoes do sistema. em tempo real. no corredor do prédio de laboratórios do Instituto de Ciências Matenáticas e de Computacão da Lniversidade de Săo Paulo.

Na Tabula 7.1 na página segninue säo apresent atos os dados refercntes a csses 
expcrimentos. Nela são apresentados o tempo médio de $\mathrm{CPL}^{-1} \mathrm{~cm}$ milisegundos gasto por ciclo para diversas quantidades de anostras utilizadas (ver Srçóo 4.3 na página 30). Un ciclo de localização é realizado a cada metro de translação on a carda $30^{\circ}$ do rotacão. Em nenhum dos asos houve falhas do localizacáo.

Tabela 7.1: Resultados da Localizaciono Local.

\begin{tabular}{|c|c|}
\hline Amostras & Tenipo de CPU \\
\hline \hline 1000 & $1302,7 \mathrm{msc}$ \\
\hline 500 & $695.9 \mathrm{mscc}$ \\
\hline 250 & $342.3 \mathrm{msec}$ \\
\hline 125 & $154.2 \mathrm{msec}$ \\
\hline 75 & $81 \mathrm{mmsec}$ \\
\hline 50 & $52.1 \mathrm{msec}$ \\
\hline 25 & $26 \mathrm{mscc}$ \\
\hline
\end{tabular}

Os resultados dos experimentos con localização global estaro dispostos na Titbela 7.2. Nela são apresentados o t.mpo médio de CPU gasto a cada ciclo do processo e a distáncia percorrida pelo robô até se localizar para diferentes configuraçōes de total de amostras e número de amostras alcatórias. Novamente em nenhum dos casos houve fallhas de localizaçào.

Tabela 7.2: Rosultados da Locializacão Global.

\begin{tabular}{|c|c|c|c|}
\hline Amostras & A. Aleatórias & Tempo de CPU & Distanncia. \\
\hline 1000 & 300 & 1054,8 msec & $6,3 \mathrm{~mm}$ \\
\hline 1000 & 200 & $1081,2 \operatorname{minse}$ & $8.1 \mathrm{~m}$ \\
\hline 1000 & 100 & 1064,7nsec: & $26.4 n$ \\
\hline 500 & 100 & $548.4 \mathrm{msec}$ & $12.6 \mathrm{~mm}$ \\
\hline 500 & 50 & 548.5 msee & $24 m$ \\
\hline 500 & 25 & $529.6 \mathrm{msec}$ & $62.4 \mathrm{~m}$ \\
\hline 250 & 50 & $257.2 \mathrm{mscc}$ & $53.1 \mathrm{~m}$ \\
\hline 250 & 25 & $275,8 \mathrm{mscc}$ & $53,2 \mathrm{~mm}$ \\
\hline 250 & 10 & $287.1 \mathrm{msec}$ & $25.1 \mathrm{~m}$ \\
\hline
\end{tabular}

Os resultados referentes a distáneia pereorrida pelo robo até se komalizar servem apenas para comparação dos diferentes parämetros de númoro de amostrás. Essa distancia é influenciada por ontros fatores. principalnente pelas características do ambiente disponíveis no momento da localizaçào. Em ambientes muito simétricos, a localização provavelmente irá levar mais tempo do que em ambientes

${ }^{1}$ Foi utilizarlo um Pentiun 4 com clock de: 2GH\%. 
assimétricos. Portanto, nesse cxperimento foram utilizados logs do robó fazendo

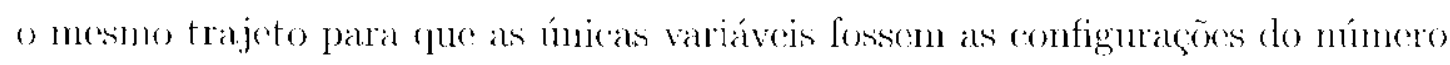
do amostras.

Tesse experimento, observa-se que não há uma relação exata entre o número de amostras e a distância mínima para realizar a localizaçăo global, porém pode-se inferir que quanto mais amostrab, maiores serào as chances de o robo se localizar rapidamente. Outra relaçào que pode ser observada é fue a relação entre o número total de amostras e o númoro de anostras aleatórias utilizadas lambém é muito importanto. Por exemplo, com j00 amostras e 100 amostras aleatórias. o resultado foi melhor do que com 1000 amostras e 100 amostras aleatólias. Quando o número de amost ras é baixo, 250 por exemplo. esisa relação parece não fumcionar. Xa verdade, rom poucas amostras é difícil encontrar qualquer relação.

Foram realizados experimentos em ambiente estático (live de pessoas cruzando o caminho to robo) e cm ambiente dinaninico. Mesmo com várials pessoas cruzando a frente do robo ao mesmo tempo. a performance do método não so degradou significalivamente, porón o sistema não foi testado em situações crítiwas com o ambiente densanente povoado. Porlanto, pode-se conctuir que para a majoria dos ambientes dinámieos o método funciona sem problemas.

\subsection{Performance do Mapeamento}

Vessa secão são apresentados alguns mapas gerados pelo método de mapeamento utilizado nosse projeto. Nlguns deles são mapas construídos em tempo real cm um ambiente real e outros são construídos com ajuda de um simulador de ambientes que faz parte da plataforma do Saphima. Esso simmlardor possui un alto gratu de fidelidade com os erros dos sensores e odométricos. O uso do simmlador facilita o teste do sistema em diversos ambientes e permite a introduça de construcoós que explorem características de annbientes difíceis de encontrar no ICAMC-USP, como por exemplo, um ambiente cícico.

En todas as figuras referentes a mapas apresentadas nessa segão é possível identificar o lrajeto do robô. Ele é representado por uma linha fina. So final da linha encontra-se a última posição do robô e uma "nuvem" de amostras representando a crença do robó sobre sua posição no fim do mapeamento.

Foi mapeado o corredor do prédio de laboratórios do hustiluto de Ciencias Malemáticas e do Computaräo da Universidade de São Paulo que possui 10 motros de comprimento. Ema planta desse prédio ć exibida na Figura 7.1 na próxima página com o corredor e áreas abertas destacados. Na Figura 7.2 na página seguinte pode ser visto o mapa gerado utilizando a técnica de Occupancy Grid 
isoladamente. F́ possivel verificar nessa figura os problemas acarretados pelos erros de odometria acumulados por trajetos longos. Nesse caso, os erros foram tào graves que o mapa gerado não pode ser utilizado para navegação, pois uma mesma área aparece majeada em lugares diferentes o algumas áreas formu apagadas pola sobreposição de outras.

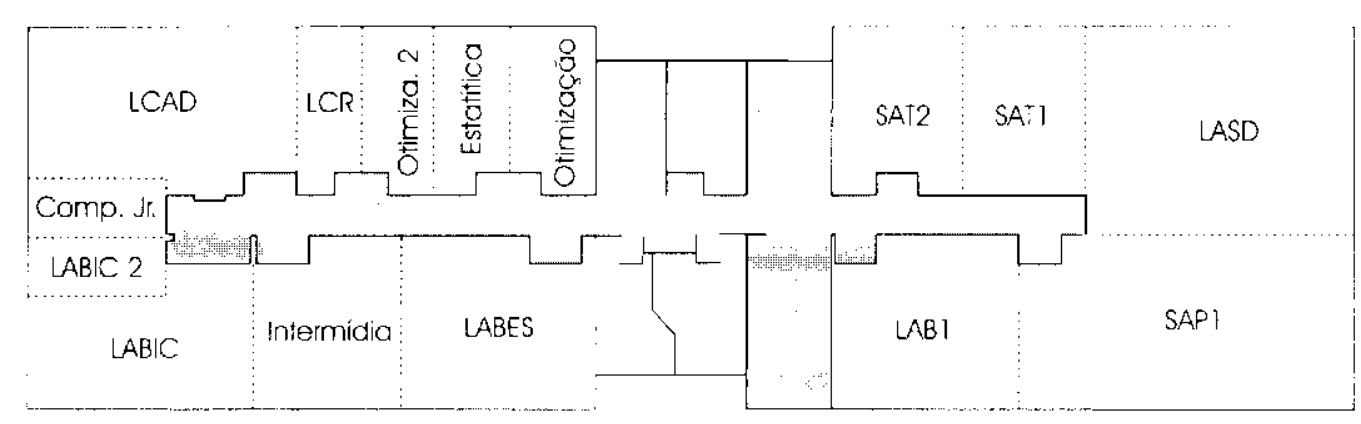

Figura 7.1: Planta do corredor do prédio de Laboratórios do ICMC-USP.

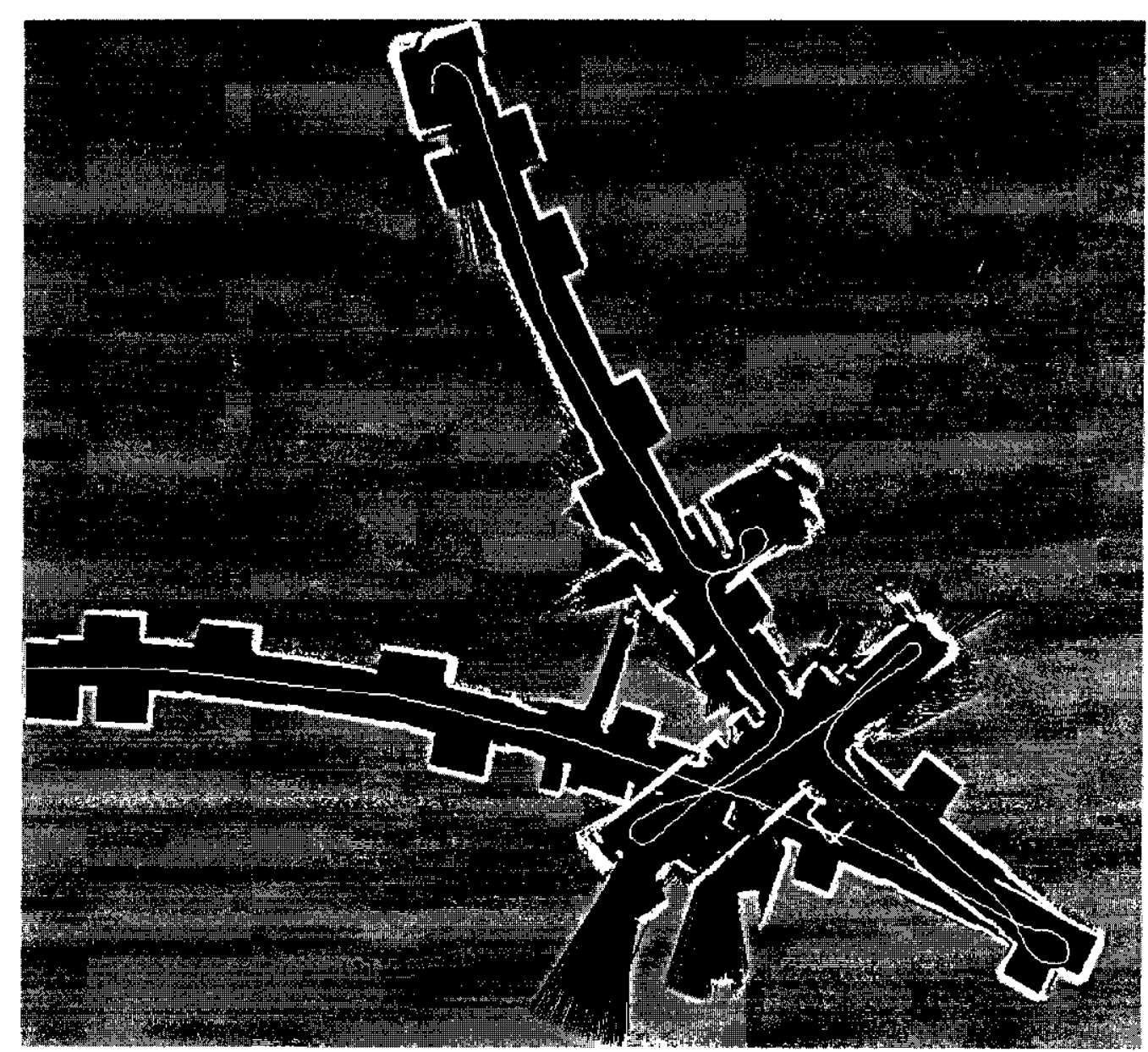

Figura 7.2: Corredor do prédio de laboratórios mapeado por Occupancy Grid. Os erros de odometria acumulados inutilizaram o mapa gerado.

Na Figura 7.3 na próxima página. utilizando o mesmo log utilizado na constru- 
cáo do mapa da Figura 7.2 na páginia opostan, o corredor foi mapeado integrando-se o métucelo Occupancy Grid com o método Localizaşäo Monte Carlo. Nessa figura. o mapa gerado apesar de não possuir una precisão nétrica absoluta, é perféitamente viável para a navegaçào do robô móvel. As áreas mais acima o abaixo. onde parece que "faltam pexlaços" do mapa são áreas por onde o robôn não passou por serem áreas externas ao prédio. Como as portas são do vidro e o sensor PLS faz as leituras do ambiente através da medição do tempo de reflexão de um sinal luminose (laser infra-vermolho). algumas áras externas são parcialmente includas no mapa, mesno con a porta fechada. É interessante notar que o mapa gerado contém informaçoes sobre móveis e outras características sutis que plantal não rẹpresenta.

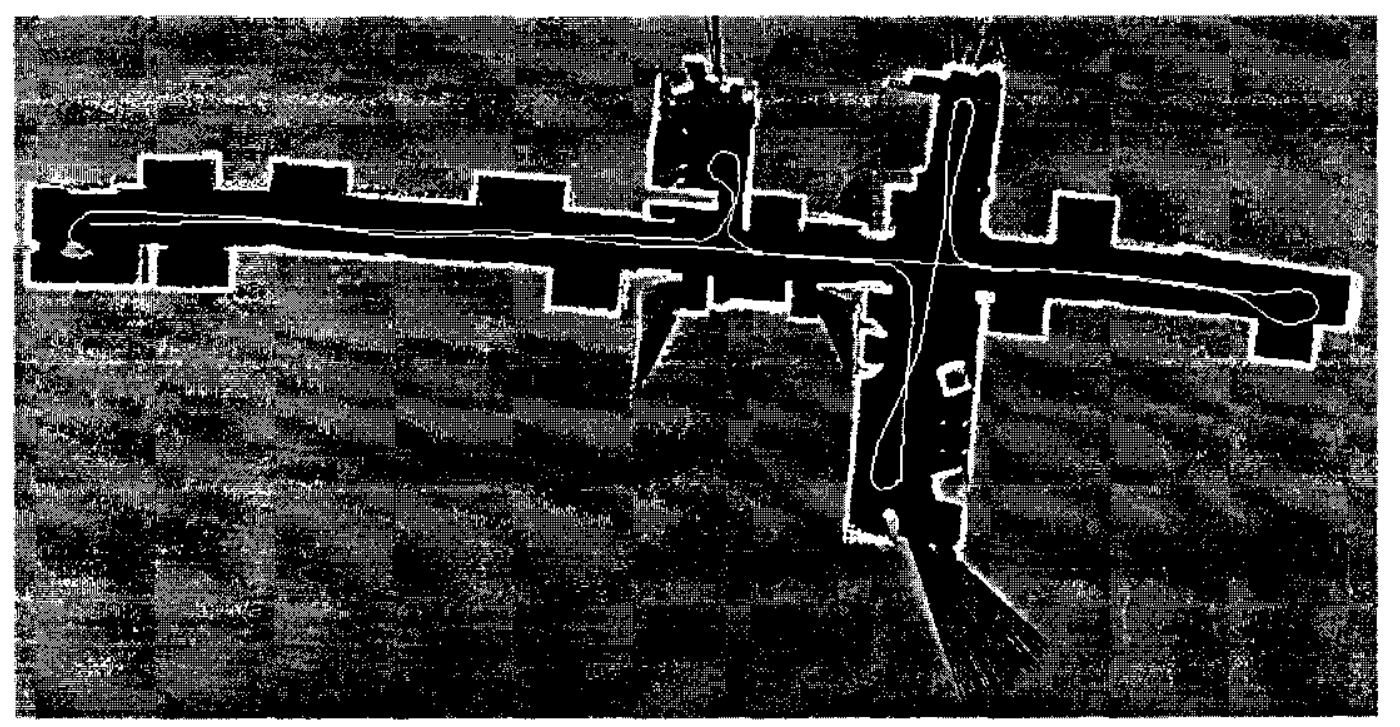

Figura 7.3: Corredor do prédio de Laboratórios mapeado por Occupancy Grids com Localização Monte Carlo.

Wapas gerados por cssa abordagem, gerahnchte são adequados a navegação mesmo estando sensivelmente distorcjdos como ć o caso da Figura 7.4 na próxima página. Apesar de não rettetir fielmente o mapa esperado por um ser humano. para o robô esse mapa contém as informaçöes necessárias para navegar por torlos os ambichtes (o cule não é possível com o mapa da Figura 7.5 na página seguinte que foi gerada com o mesmo log, porén sem utilizar o método de localização Monte Carlo). Utilizando o método de localização Monte Carlo com essc mapa, o robô pode saber sua localização a cacla instante. Pode se então utilizar urn mapa licticio (on una lista de hocais), com un visual mais cativante para o usuário na interface e relacionar essa representação a pontos específicos do mapa métrico utilizado pelo robô.

O maior problema dessa abordagen é a construção de mapas em grandes 


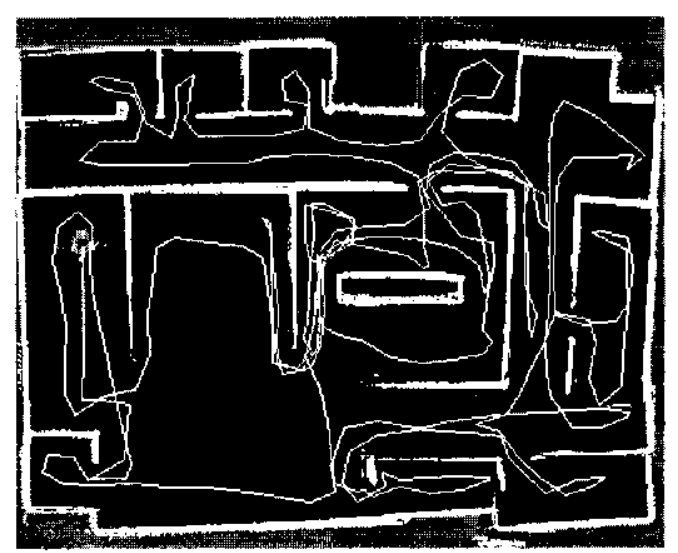

Fïgura 7.4: Mapa com correção de posição de um ambiente simnulado contendo unn ciclo.

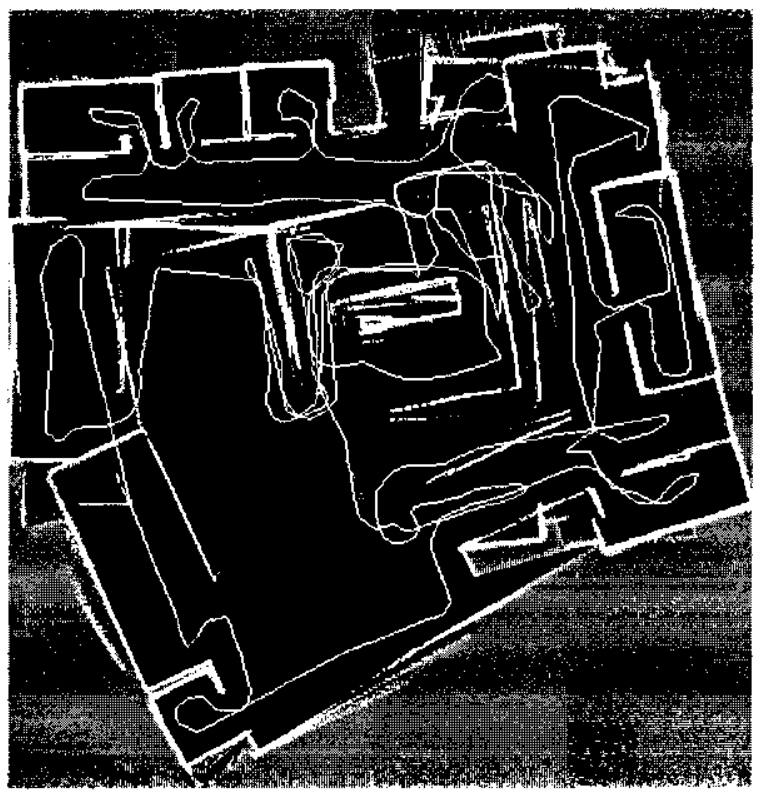

Figura 7.5: Mapa sem rorreção de posição de um ambiente simulado contende 1111 ciclo.

ambientes cíclicos. Um ambionte cíclico ó aquele on que so pode chegar a un mesmo ponto por dois caminhos diferentes. O problema é mais grave quando os caminhos em questão não compartilham paredes como. por exemplo, um circuito oval. Nesse caso, como um caminho não terá o outro como referência para a

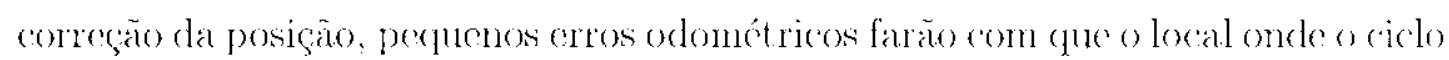
deveria ser fechado seja representado por posiçón diferentes cm cada caminho.

Outro fator agravante ó a falla de caracteristicas discriminalutes no ambiente como em um longo corredor onde as duats paredes siéo lisas.

Lima sitnação extremamente problemática pode ser vista na Figma 7.6.b que apresenta o mapa gerado om um ambiente simulado que é cíclico com corredores 
longos " de paredes lisas. Felizmente esses problenas só ocorrem se o ambiente

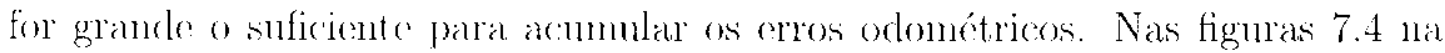
página anterior a 7.6.a podem ser vistos exemplos do ambientes simulados que contén ciclos onde năo houveram problemas.

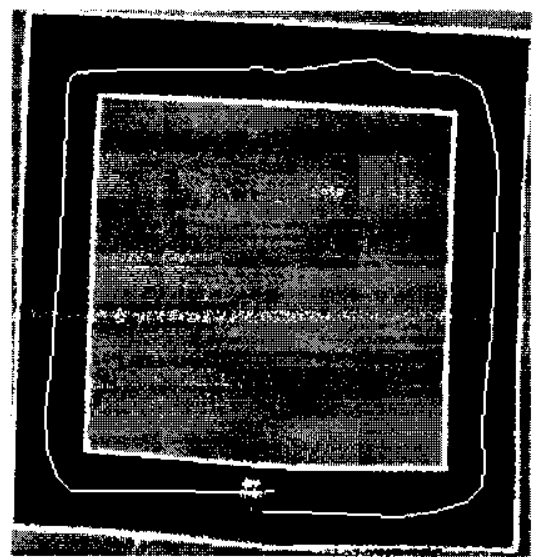

(a)

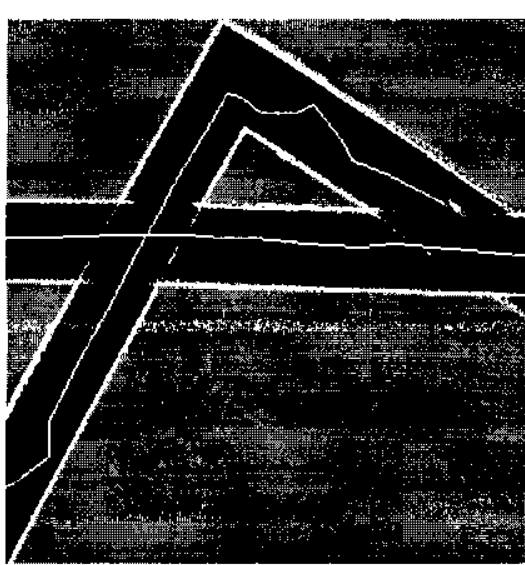

(b)

Figura 7.6: a) Um ambiente cíclico relativamente pequeno onde o ero não foi grave. b) Detalbe do ponto onde deveria ser feito o fechamento do ciclo em um ambiente très vezes maior que o ilustrado om (a).

\subsection{Performance do Controle de Trajetória}

Na Figura 7.7 e na Figura 7.8 na próxima página, pode ser visto a trajetória utilizada pelo método VFH para conduzir o robô entre os pontos definidos pelo usuário do sistema. O método VFH sempre que possívol tentará controlar o robô para que ele se desloque em linha reta. Ele somente desvia o curso do robô quando há ohstáculos entre a meta o o robô.

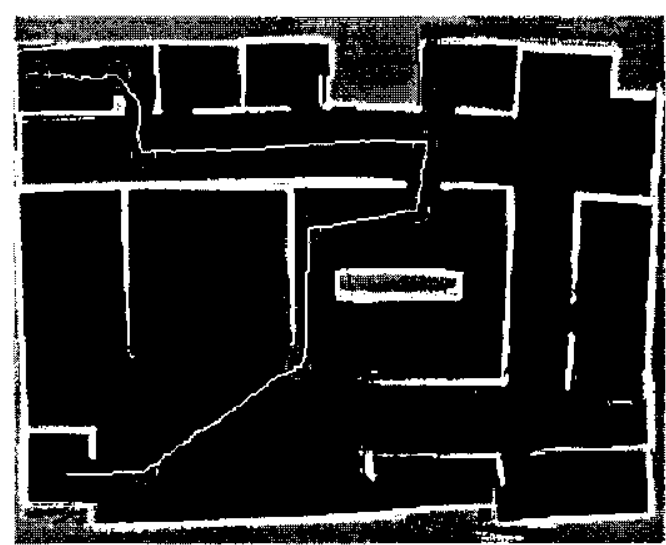

Figura 7.7: Caminho percorrido pelo robò em um ambiente simulado para passar pelos pontos (ćrculos) definidos pelo usuário. 


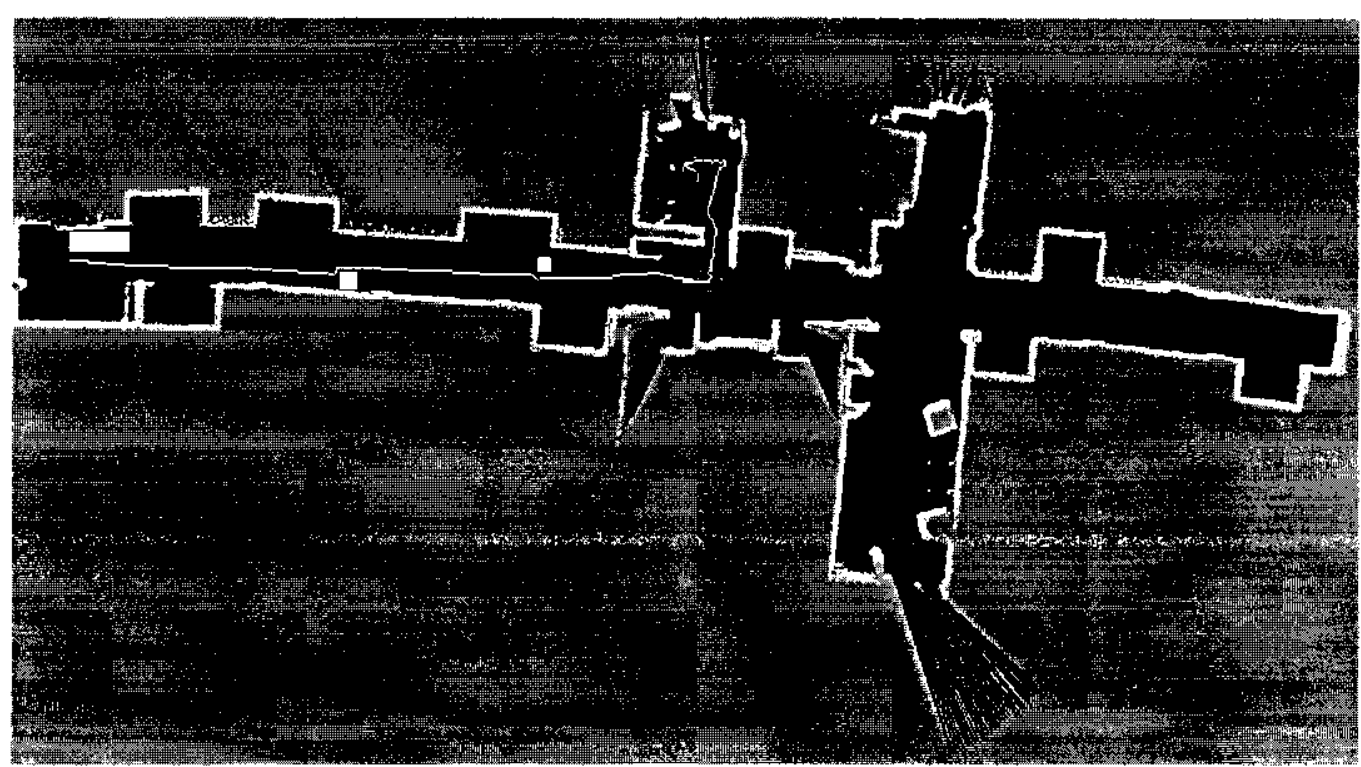

Figura 7.8: Caminho percorrido pelo robô en um ambiente real para passsar pelos pontos (érrenlos) definidos pelo nusuário. Nesse caminho o robó encontron três obstáculos (rotângulos) năo previstos no mapa.

O principal problena desse método é que ele nào consegue fazer com que o robô vá de um ponto a qualcuer outro ponto no mapa. So a meta for definicla atrás de uma parede maior que a região ativa (ver Seção 5.2 na página 35 ) de provavelnente irá fazex enon que o robó fique inclo de um lado para o outro em uma pequena região atrás da parede e munca encontrará a passagem para o outro lade, onde se encontra a meta. Esse problema também é compartilhado com o método Campos Potenciais.

Una alternativa para esse problema é a de utilizar um planejador e'm um nível de abstração acima do método de controle de trajetória utilizado. Esse planejador deverá não somente dividir o caminho até a metal en submetas bascancle-so na menor distancia, mas também bascando-se no contecimento das linitaçoes do método de controle de trajetória. Desse modo, reduz-se as possibilidades do robó parar seu progresso em direção a meta. deixando apenas o desvio de obstáculos dinânuicos e monores como pessoas passando pelo caminho o objetos nầ mapeados colocados temporariannente? no ambiente.

Como dito anteriormente em nossa implementaço at laal. o usuário fak o papel do planejador, indicando os pontos pelos quais o robo deve passar para chegar até sua meta do forma segura. Na Figura 7.7 na página precedente e na Figura 7.8 . os círeulos representan esses pontos. 


\subsection{Considerações Finais}

Fisse capítulo apresentou os resultados obtidos com o desenvolvinento desse projeto. Com baso nesses resultados é possivel verificar que os métodos probabi

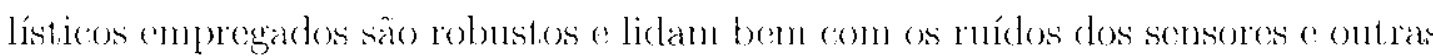
fontes de incerteya. IIma descriço desses resultados também pode ser encontrada em (Bianchi and Romero, 2003). No capítulo seguinte é apresentado um resumo das conclusoes obtidas durante o desenvolvinento desse trabalho e são propostos diversos traballose futures. Isso indica que esse a apenas o início de numa série de trabalhos a werem realizados, na área de: mótodes probabilisticos para robos móveis, no Laboratório de Inteligencia Computacional (IABIC) do ICMC-LSP 


$$
\text { , }
$$




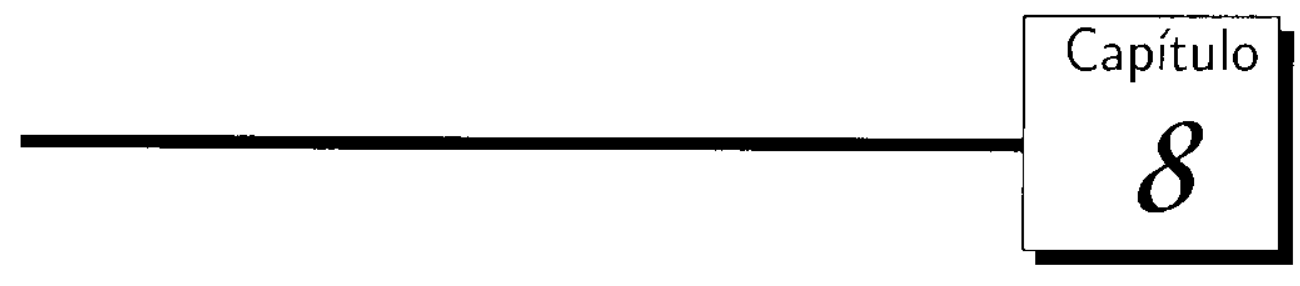

Conclusões e Trabalhos Futuros

Fsse trabalho resulton em un sistema de navegaçào para robós móveis que ntiliza métodes probabilísticos para lidar explicitanente com a incerteza inerente aos sensores a atuadores utilizados pelo robô.

Os resultados apresentados confirmann que, para os fins de transporte documentos en um ambiente não estruturado como un prédio de laboratórios, esses mótodos sìno indequarlos.

A localização milizando o método Monte Carlo ó muito robusta e flexível. Sua capacidade de localizar o robò globalmente confere ao robô um nível a mais de autonomia, sondo (apaz de se recuperar de falhas. Além disso, de possui a habilidade de se adaptar aos recurson computacionais existentes.

O método de mapeamento utilizando Occupancy Grid associado ao método de localização Monte Carlo é rápido e pode ser aplicado em tempo real, diminuindo consideravelmente o tempo de implantação do sistenna en 1 nn novo ambiente. Contudo, por näo possuir una precisão métrica absoluta, pode nä́o ser eficarz ao mapear um ambiente cíclieco (aso o ciclo seja muito grande, una vo\% que os pequenos crros odométricos năo compensados podem fazer con que um ciclo năo seja fechado como deveria. Já encontra-se em desenvolvinento por um outro membro do grupo mon método de mapeamento cue possa lidar com esse tipo de ambiente de maneira mais satisfatória.

Verificanos também os problemas com os métodos de controle de trajetória reativos como os Canpos Potenciais e o VFH e percebemos que um planejamento deliberativo que leve em consideracäo as frapuezals desse método pode elevar o

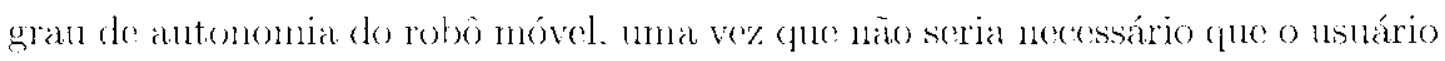
definisse pontos intermediários centre a posição inicjal do robô e a meta.

Como trabalho futuro, pretende-se desenvolver um mapeamento topológico sobre o mapa métrico descrito nesse trabalho conforme a abordagen de Thrun 
(1998b) e usar esse mapa topológico para realizar o planejamento de trajetórias. Poderá ser investigada a possibilidade de incorporacão de algoritmos de: Otinização para estimar molhores caninhos entre o local de origem e destino.

Outro trabalho futuro está na area da interaçäo de usuário com o robô. Uma interface web para controle do robô deverá ser desenvolvida para o sistema de entrega de documentos. Além disso, aspectos da interaçäo do robô com as pessoas que cncontrar em seu ambiente também devem ser estudados.

As contribuiçōes desse trabalho foram. primeiramente, o estudo de métodos probabilísticos para a navegaçño de robôs móveis, uma area que, até o linnite de nosso conhecimento, é pouco explorada no Brasil. O presente trabalho inicia majs essa linha de pesquisa no Laboratório de Inteligencia Computacional (LABIC) do ICMC-USP. Além disso, o estudo, especificação o implementação de modificaçõos uo hardware robótico disponível no LABIC, realizado con a adaptaçäo do sentsor SICK PIS ao robô Pioneer 1 e a implementação de um módulo de software para a comunicação com cesse dispositivo, facilitará a implementação de novos trabalhos nessa área.

Uma outra contribuição foi o desenvolvimento do sistema de navega(ção. Os módulos desse sistema foram desenvolvidos seguindo o paradigma de orientaçăo a objetos, em classes com funçoes bem definidas apresentando alta coesäo funcional e baixo acoplamento de dados. Dessa forma. una arquitetura básica para o desenvolvimento de aplicaçoes robóticas, baseadas on navegacão, foi criada. (? con cla foi implementada a aplicação do transporte de documentos. porén, outras aplicações poderão ser implementadas utilizando essa arquitetura. Dessa forma. essce sistema servirá cono semente para vários sistemas que scrão desenvolvidos nessa linha de pesquisa como apontado pelas propostas de trabalhos futuros. 


\section{Referências Bibliográficas}

Arkin. R. (1998). Bchawior-Based Robotics. MIT Press.

Barraquand, J. and latombe, J. (1991). Robot motion planning: A distributed representation approach. Intemational Journal of Robotics Restarch 10:628 649.

Bianchi, R. F. and Romero. R. A. F. (2003). Robo mensageiro bascado em navogacào probabilística. In Submetido ao VI Simpósto Brasiletro de Automacáo Inteligente, Bauru.

Borenstcin, J., Everett, B., and Feng. L. (1996). Nawigating Mobile Robots: Sys.tem.s and Techniques. K. Peters Ltd., Wellesley, MA.

Borenstein. J. and Koren. Y. (1991). The vector field histogram - fast obstacke avoidance for mobile robots. IEEE Thansactions on Robotics and Automation, $7(3): 278 \cdot 288$.

Brooks, R. A. (1991). Intelligence without reason. In Myopoulos, John; Reiter, R., cditor. Procecdings of thr: 12th International Jomt Conference on Artificial Intelligence. prages 569-595. Sydney, Australia. Morgan Kaufmamn.

Cox. I. .J. and Wilfong. G. T. (1990). Autonomous Robot Vehicles. Springer Verlag. New York.

Cox, I. J. (1991). Blanche: an experiment in guidance and navigation of an autonomous robot vehicle. IEEE Transactions on Robotics and Automation, $7(2): 1932204$.

Elfes. A. (1989). Using occupancy grids for mobile robot perception and navigation. IEEE Computer, 22(6):46-57.

Everett, 1I. R. (1995). Sensors for Mobile Robots. A K Poters.

Foley, J. D., van Dan, A., Feiner, S. K., and Inghes. J. F. (1995). Computer Ciruphics: Principles and Practice. Addison-Wesley Pub Co. 
Fox, D., Burgard, W., Thrun, S., and Cremers. A. B. (1998a). Position estimation for mobile robots in dyuamic onvironments. In $A A A I / I A A I$, pages 983988.

Fox. D., Burgard. W., and Thrun. S. (1998b). Active markov localization for mobile robots. Robotics and Autonomous Systems, 25:195 207.

Fox, D., Burgard, W., and Thrum, S. (1999). Warkov localization for mobile robots in dynamic environments. Journal of Artificial Intelligence Research. (11):391 427 .

Iloward. A., Mataric, M. J., and Sukhatme. G. S. (2002). Mobile sensor network deployment using potential ficde: A distributed, salable solution to the area coverage problem. In 6th International Symposium on Distributed Autonomous Robotices Systems, Fukuokia. Japan.

Koren, Y. and Borenstein, J. (1991). Potential field mothods and their inherent limitations for mobilo robot navigation. In IEEE Conference on Robotics ane Automation, pages 1398-1404, Sacramento. California.

Kortenkanup, D., Bonasso. R. P., and Murphy, R. (1998). Artificial Intelligence and Mobile Robots: Case Studies of Sucessful Robot Systems. AMI/ MII Press.

Lee, 1). (1996). The Map-Building and Exploration Strategies of a Simple SonarEquipped Robot. Cambridge University Peters.

Murphy, R. R. (2000). Introduction to AI Robotics. MIT Press.

Olson, C. F. (2000). Probatsilistic self-localization for mobile robots. IEEE Transactions On Robotics And Automation. 16(1):5ij 66.

Rimon, F. and Koditschek, D. (1992). Exact robot navigation using artificial potential functions. IEEE Transactions on Robotics and Automation. 8:501 $\overline{3} 18$.

Shanahan. M. (1999). Reinventing shakey. In Minker, .T. editor, Workshop on Logic-Based Artificial Intclligence. Washington. ICC. Inne 14 16. 1999. College Park, Maryland. Computer Science Department. University of Maryland.

Simmons, R. G., Goodwin, R.. Haigh. K. Z.. Koenig, S.. O'Sullivan, J., anrl Veloso, M. M. (1997). Xavier: Experience with a lavered robot architecture. To appear in the ACM magazine Inielligence. 
Thrum. S., Fox. D., Burgard, W., and Dellaert. F. (200)a $)$. Robust Monte Carlo localization for mobsile robots. Texhnical report, Garnegie Mellon University.

Thrmu. S. Fox, D. and Burgard. W. (2000b). Probubilistr: Robotics. Early Draft.

Thum. S. (1998a). Bayesian landmark learning for mobile robot localization Machine Learning, 33:41.

Thrun, S. (1998b). Learning metric-topological maps for indoor mobile robot navigation. Artifical Intelligence, 99(1):21 71 .

Urich, I. and Borenstein. J. (2000). VFH*: Local olstacle avoidanee with look-

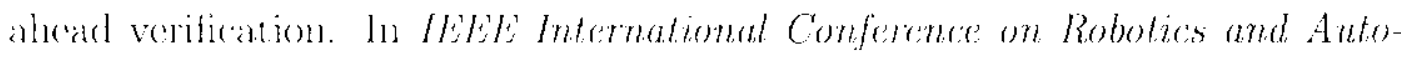
matuon. pages 2505 2511, San Francisco, (A A 